\title{
Cardiovascular Magnetic Resonance in Marfan syndrome
}

\author{
Helen Dormand ${ }^{1}$ and Raad $\mathrm{H}$ Mohiaddin ${ }^{2^{*}}$
}

\begin{abstract}
This review provides an overview of Marfan syndrome with an emphasis on cardiovascular complications and cardiovascular imaging. Both pre- and post-operative imaging is addressed with an explanation of surgical management. All relevant imaging modalities are discussed with a particular focus on cardiovascular MR.
\end{abstract}

Keywords: Marfan syndrome, Aorta, CMR, CT, Echo

\section{Introduction}

Marfan syndrome (MFS) is a disorder of connective tissue structure and function, with a reported incidence of approximately 1 in 5000 individuals [1]. With no predilection for gender or ethnicity the UK prevalence is in the region of 10,000. In 1896, Professor Antoine Bernard-Jean Marfan, founder of paediatrics in France, described a 5 year old girl with disproportionately long limbs and digits and called the condition, dolichostenomelie (slender limbs). His subsequent work led to the eponymous naming of Marfan syndrome, (although this 'index case' is now felt to represent congenital contractural arachnodactyly, a phenotypically similar but separate condition) [1]. However, it was not until the 1930's that the associated cardiovascular complications began to be recognised in the Western medical literature.

Other pathologies overlap clinically with Marfan syndrome. In ectopia lentis syndrome, lens dislocation occurs without the associated cardiac abnormalities; with familial thoracic aortic syndrome, aortic pathology exists without other features of MFS and Loeys-Dietz syndrome.

With our understanding of phenotypic variance, internationally agreed clinical criteria were defined, initially in 1986 (Berlin nosology) [2] and later revised in the Ghent nosology of 1996 [3]. A further revision of the guidelines proposed aortic root aneurysm and lens dislocation as cardinal clinical features [4], see Table 1 and 2 (A web based

\footnotetext{
* Correspondence: r.mohiaddin@imperial.ac.uk

${ }^{2}$ Royal Brompton Hospital and National Heart \& Lung Institute, Imperial College, Sydney Street, London SW3 6NP, UK

Full list of author information is available at the end of the article
}

diagnostic tool for application of these criteria is available at www.marfan.org).

\section{Genetic basis and pathogenesis}

MFS is an autosomal dominant condition exhibiting complete penetrance but variable expression. Up to one third of cases are thought to be spontaneous mutations, higher than previously thought [5,6]. Rarer recessive conditions displaying the MFS phenotype have also been described [7]. In the majority of cases a mutation in the fibrillin 1 (FBN1) gene located on chromosome 15 causes the fibrillinopathy [8]. The fibrillin glycoprotein was discovered in 1986 and linked in 1991 to the FBN1 gene, chromosome 15 and MFS [9]. FBN1 molecular analysis, now in clinical practice, provides valuable diagnostic information, particularly in children in whom aortic dilatation may not initially be present [10].

Histological abnormalities in the aortic wall were recognised by the 1950's and descriptions can be found of disrupted elastic lamella; disorganised and hypertrophied smooth muscle fibres with increased vascular channels from the media to adventitia [11]. Over time, refined histological study revealed degradation of the extracellular matrix referred to previously as 'cystic medial necrosis' [12].

Fibrillin1 is a major component of 10-12 nm microfibrils which are an integral part of elastic connective tissues. They have complex structural, expansile and anchoring roles which are yet to be fully elucidated [9]. However, MFS is not merely a consequence of inherently weakened connective tissue as originally thought. Instead evidence from murine models now points towards an additional failure of appropriate maintenance of elastic fibres (Figures 1 
Table 1 Simplified revised Ghent criteria

\begin{tabular}{llll}
\hline $\begin{array}{l}\text { In the absence of } \\
\text { a family history: }\end{array}$ & $\begin{array}{l}\text { Diagnosis } \\
\text { of MFS }\end{array}$ & $\begin{array}{l}\text { In the presence of } \\
\text { a family history: }\end{array}$ & $\begin{array}{l}\text { Diagnosis } \\
\text { of MFS }\end{array}$ \\
\hline $\begin{array}{l}\text { Aorta ( } Z \geq 2 \text { or dissection) } \\
\text { and ectopia lentis }\end{array}$ & Yes & Ectopia lentis & Yes \\
$\begin{array}{l}\text { Aorta ( } Z \geq 2 \text { or dissection) } \\
\text { and a causal FBN1 mutation }\end{array}$ & Yes & Systemic score $\geq 7$ & Yes \\
$\begin{array}{llll}\text { Aorta ( } Z \geq 2 \text { or dissection) } \\
\text { and systemic features }(\geq 7)\end{array}$ & Yes & $\begin{array}{l}\text { Aorta }(Z \geq 2 \text { above } \\
20 \text { yr old, } Z \geq 3\end{array}$ & Yes \\
below 20 yr, or & \\
dissection) & \\
$\begin{array}{l}\text { Ectopia lentis and a causal } \\
\text { FBN1 mutation and }\end{array}$ & Yes & & Yes \\
aortic aneurysm & & & \\
\hline$Z$-score is dive & & & \\
\hline
\end{tabular}

$Z$-score is derived from a measurement of the sinus of Valsalva indexed to body surface area.

Caveat: other conditions such as Loeys-Dietz syndrome must be excluded.

and 2). Latent transforming growth factor- $\beta$ (TGF- $\beta$ ) binding protein dysregulation by microfibrils is an important mechanism in MFS pathogenesis and can explain the phenotypic features found in many connective tissues $[13,14]$. The proteases involved in extracellular matrix degradation have also come under scrutiny and recent work has focused on matrix metalloproteinases and serine proteinases. These are implicated in all thoracic aneurysmal syndromes, not just MFS. In the aorta the defective tissues have increased alcianophilic glycosominoglycans, vacuoles secondary to the loss of smooth muscle cells and disordered adhesive protein. This renders them more susceptible to shear stress leading, over time, to dilatation and dissection.

\section{Table 2 Scoring of systemic features}

\begin{tabular}{ll}
\hline Feature & Score \\
\hline Wrist and thumb sign & 3 \\
Wrist or thumb sign & 1 \\
Pectus carinatum & 2 \\
Pectus excavatum/asymmetry & 1 \\
Hindfoot deformity & 2 \\
Plain pes planus & 1 \\
Pneumothorax & 2 \\
Dural ectasia & 2 \\
Protrusio acetabuli & 2 \\
Reduced upper/lower segment ratio and increased & 1 \\
arm span/height and no severe scoliosis & 1 \\
Scoliosis or thoracolumbar kyphosis & 1 \\
Reduced elbow extension & 1 \\
Facial features (3/5) & 1 \\
Skin striae & 1 \\
Myopia > 3 diopters & 1 \\
Mitral valve prolapsed & 1 \\
\hline
\end{tabular}

Maximum total 20

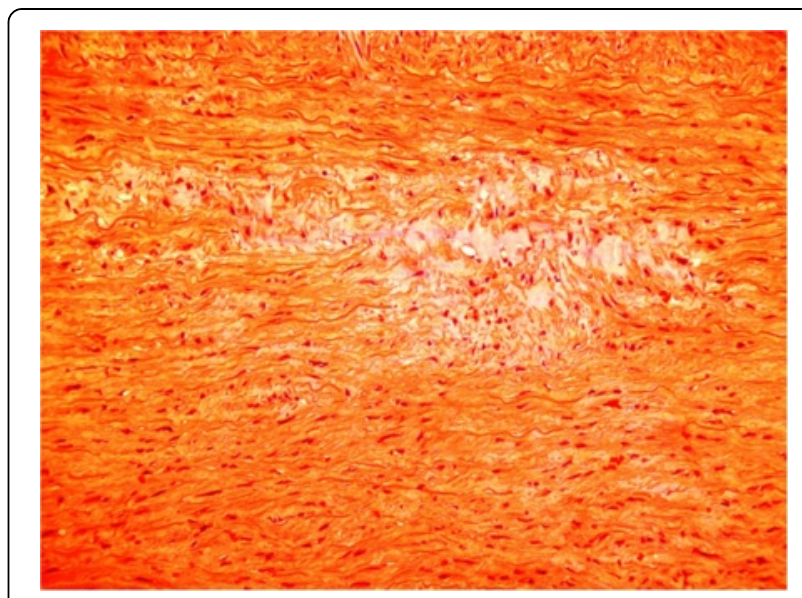

Figure 1 Haematoxylin and eosin stain showing cystic change in the vascular media in MFS.

\section{Systemic manifestations of MFS}

The systems classically thought to be affected by MFS are cardiovascular, ocular and skeletal (see Table 1). Cardiovascular manifestations, particularly aortic dissection are the most common cause of death. Cardiovascular imaging is therefore fundamental to the screening, diagnosis and lifelong monitoring of these individuals.

Upward subluxation of the lens (ectopia lentis) may be present in up to $80 \%$ patients; there is a tendency to myopia and an increased risk of retinal detachment [5]. Annual ophthalmological evaluation is advised. Although skeletal features may be most noted by clinicians, they feature less prominently in revised diagnostic guidelines and include dolichostenomelia (increased length of the limbs as compared with the trunk), arachnodactyly, scoliosis, pectus excavatum (Figure 3 ) or carinatum and dural ectasia (Figure 4). Pneumothorax and skin striae are also recognised systemic features.

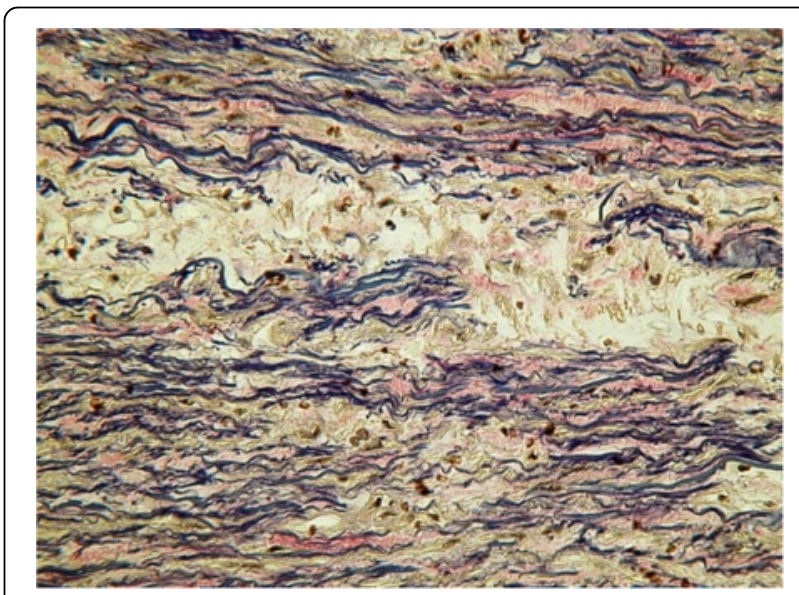

Figure $\mathbf{2}$ Trichrome stain where elastic fibres are black showing their destruction and fragmentation. 


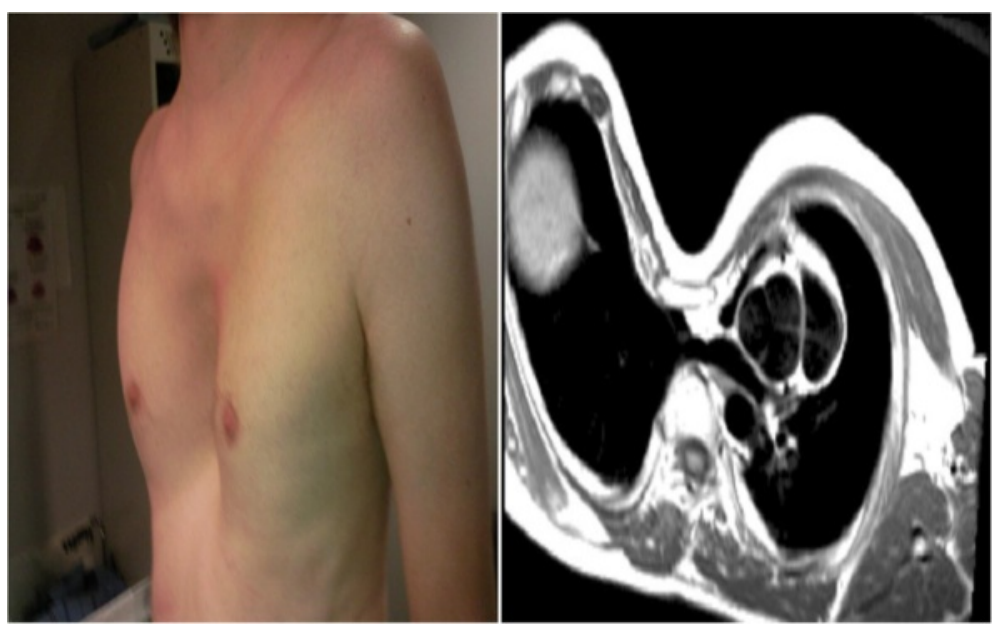

Figure 3 Pectus Excavatum in panel on the left with corresponding CMR image on the right.

\section{Phenocopies of MFS}

The diagnosis of MFS is complicated by its overlapping phenotype with other conditions and is best made by an expert in this area, following internationally agreed criteria. For example, Professor Marfan's index case is now thought to have had congenital contractural arachnodactyly which is related to mutations in the gene encoding for fibrillin 2 [12]. It is still fairly recently that Loeys-Dietz syndrome was recognised and is characterised by arterial tortuousity and aneurysms, hypertelorism, and bifid uvula or cleft palate. It is caused by heterozygous mutations in the genes encoding for transforming growth factor $\beta$ receptors 1 and 2 (TGFBR1, TGFBR2). Individuals with this autosomal dominant condition have aortic aneurysm formation and dissection at a much younger age than those with MFS and require annual MR of the vasculature from cerebrum to pelvis [15].

When mutations in fibrillin genes or TGFBR1 or 2 are present without full phenotypic features of MFS or Loeys-Dietz, then individuals may be classified into any number of groups including ecoptia lentis syndrome and MASS syndrome (mitral, aortic, skeletal, skin), with

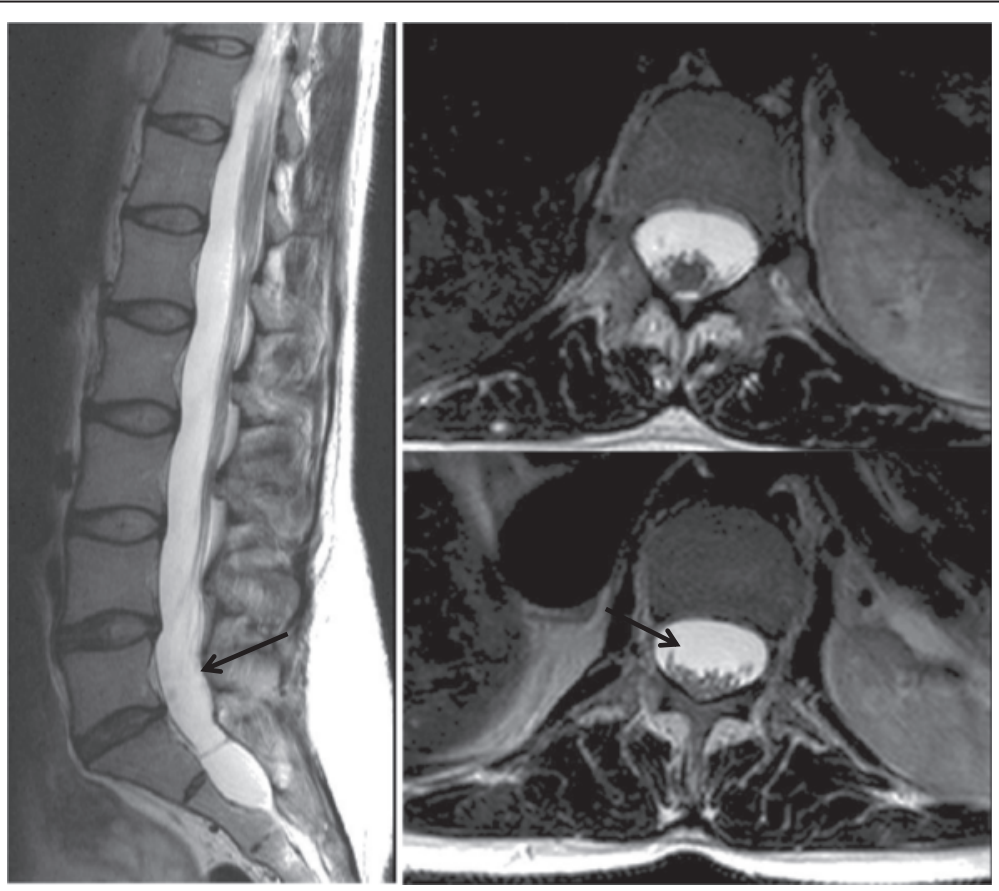

Figure 4 CMR demonstrating dural ectasia. This is ballooning or widening of the dural sac and has been the subject of various classifications It may be associated with herniation of the nerve root sleeves through their associated foramina [134]. See arrows. 
some requiring imaging, particularly children in whom vascular features may present later and the diagnosis be changed. Type IV Ehlers-Danlos syndrome also predisposes to aortic dissection.

Significant numbers of thoracic aortic aneurysms are thought to follow an inherited pattern, even when no named syndromic cause can be identified, and screening for aortic and cerebral aneurysms in first degree relatives of affected individuals has been advocated [16].

\section{Treatment and prognosis in MFS}

Medical therapy to reduce the rate of aortic dilatation and risk of dissection, once MFS has been diagnosed, is now advocated. Although experiments in turkeys over 50 years ago demonstrated that propranolol was effective in reducing death from dissecting aortic aneurysms [17], initial work in humans was not as successful [18]. Therefore it was not until 1994 that beta - blockade with propranolol was shown to be effective in slowing the rate of aortic dilatation and reducing the rate of complications in some people with MFS [19]. The beta-blocker should be titrated to effect, aimed at a heart rate after submaximal exercise of $<100$ beats/min in those over 5 years of age. Resting heart rate should be $<60$ beats/min if blood pressure will allow [6]. The rationale behind this therapy is one of reducing aortic wall shear stress by reducing the rate of pressure change in the aortic root and heart rate [20]. Subsequent work in a murine model of MFS demonstrated that losartan was effective in reducing aortic pathological changes and dilatation. Retrospective analysis in a group of paediatric patients with MFS appears to support this finding [21]. There is also evidence demonstrating that the ACE inhibitor perindopril reduces both aortic stiffness and aortic root diameter in MFS when taken in addition to beta-blockers [22]. Several randomised controlled trials are currently underway to evaluate the role of angiotensin receptor blockers and beta-blockers in MFS and should add considerably to our knowledge base.

If aortic dissection does occur then it constitutes a medical emergency. The majority of cases are Type A dissections usually necessitating surgery. Surgical treatment for aortic complications of Marfan syndrome continues to progress and will be discussed separately in the review. Lifelong imaging is recommended after aortic root surgery.

Exercise restriction may be recommended on an individual basis a part of the management of MFS and guidelines are provided by both the National Marfan Foundation (www.marfan.org) and the American Heart Association/ American College of Cardiology task forces [23].

Earlier reports quoted a mean age at death of 32 years [24] and more recently 40 years [25]. This significant increase in life expectancy has been driven by medical and surgical intervention and the median cumulative probability of survival,(age at which half of a cohort would still be alive), has risen to around 70 years [26]. It has been recognised for some time that a family history of severe cardiovascular disease in MFS is associated with increased aortic diameter and decreased survival in individual patients [27].

\section{Cardiovascular complications}

The significance of morphological cardiovascular manifestations in MFS was recognised early on [28]. They may be categorised as affecting the aorta, myocardium, valves or pulmonary arteries (see Table 3 for frequency). More recently the impact of skeletal abnormalities on cardiac function has been appreciated [29,30]. All need to be investigated by imaging.

\section{Aorta}

In MFS, the aorta becomes the critical ground for the interplay between structural microfibril matrix abnormalities, heightened by failure of standard maintenance programmes by TGF $\beta$, and beat to beat haemodynamic stressors. Endothelial shear stress, wall strain, torsion and intrinsic wall stress make this a dangerous environment for abnormal connective tissue. The result is a thinned aortic wall which progressively dilates and loses distensibility thereby heightening the risks of aneurysm formation and dissection throughout its length, but particularly at the root [6].

Cohort studies have shown that nearly $60 \%$ of those with MFS have root dilatation at a mean age of 35 years, with lower rates of more distal dilatation [31]. A review of patients with an FBN1 mutation, 73\% of whom had MFS, demonstrated that the risk of ascending aortic (AA) dilatation increases with age, reaching $96 \%$ by the age of 60 years. Men were at higher risk than women for AA dilatation, dissection or surgery [32].

Dissection is said to have occurred when the media is separated from the other aortic layers due to bleeding within and along the wall of the aorta. This is usually secondary to an intimal tear. It can be classified anatomically according to whether the ascending aorta is involved or by the site of the intimal tear, (Figure 5). This classification is important in clinical decision-making.

Dissection is acute if less than 2 weeks between onset of symptoms and presentation; subacute if 2 to 6 weeks gap; and chronic if more than 6 weeks has elapsed [33].

Table 3 Frequency of cardiovascular involvement in adults with MFS

\begin{tabular}{cc}
\hline $\begin{array}{c}\text { Aortic root/Ascending } \\
\text { aorta/Arch/Descending aorta }\end{array}$ & $\mathbf{5 8} \% / \mathbf{1 9} \% \mathbf{1 6} \% \mathbf{1 5} \%$ \\
\hline Left ventricular impairment & $25 \%$ \\
Mitral/Aortic Valves & $80 \% / 50 \%$ \\
Pulmonary Artery Dilatation & $10 \%$ \\
\hline
\end{tabular}

For references see relevant section below. 

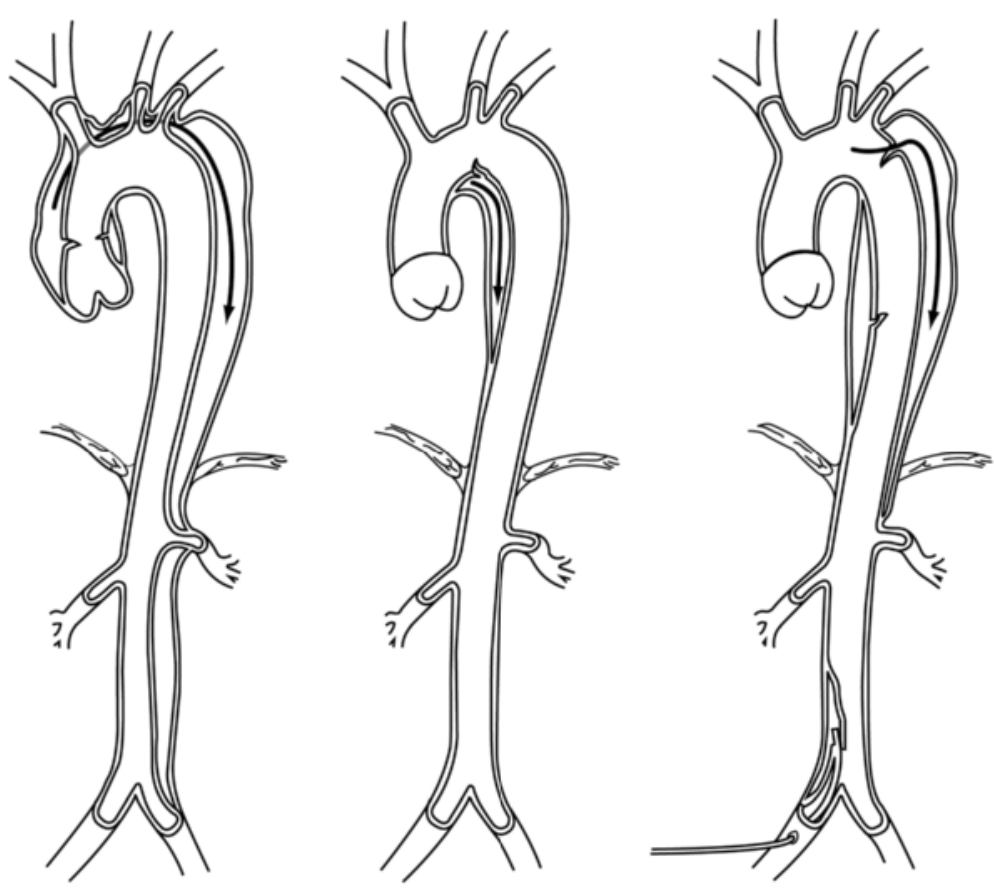

Figure 5 Stanford and De Bakey classification of aortic dissection. The image on the left represents De Bakey I and II/Stanford A; the middle image Stanford B; the right image De Bakey Illa and b/Stanford B. De Bakey l; -origin in ascending aorta; extends to include at least arch; -usually surgical management. De Bakey II; -originates in and is confined to ascending aorta; -usually surgical management. De Bakey Illa; -originates in descending aorta; usually extends distally; -usually nonsurgical management De Bakey IIlb; -originates in descending aorta; extends distally below diaphragm; -usually nonsurgical management. Stanford A; -all dissections involving ascending aorta; -management usually surgical. Stanford B; -all dissections not involving ascending aorta; -management usually nonsurgical.

Similarly, the complications of dissection may also be acute, subacute or chronic.

Acute aortic dissection usually presents with pain, although around $6 \%$ of all dissections are painless but associated with increased mortality [34]. Approximately one quarter of those with untreated proximal dissections die within $24 \mathrm{hr}$ of initial presentation. Death is usually from acute severe aortic regurgitation, aortic rupture or major branch vessel compromise.

Of those experiencing pain, it is usually midline and may be in the chest, back or abdomen depending on the location of the dissection. Onset is usually abrupt but only around half of patients describe the classical 'tearing' or 'ripping' quality so often highlighted at medical school. If this pain abates but then recurs it may indicate dissection extension and impending aortic rupture [35].

As extension occurs it may directly involve the walls of branch arteries. Alternatively branches may be compressed by expansion of a false lumen. Either mechanism leads to end organ compromise and additional systemic manifestations.

If the root is involved then aortic regurgitation may occur, as may pericardial effusion. Cardiac ischaemia may be the result of coronary artery involvement. However, regional wall motion abnormalities may occur as a result of generally low coronary perfusion pressures. Involvement of head and neck vessels can manifest as stroke or peripheral ischaemia. Peripheral ischaemia will lead to localising pain, pallor, paraesthesias and pulselessness of upper or lower limbs. Pulse deficit occurs in around $30 \%$ of patients and is associated with a poorer prognosis [36].

When renal ischaemia is present, there may be pain, haematuria, fever and biochemical abnormalities. The left renal artery is compromised more often than the right. If mesenteric ischaemia is present then there may be pain out of proportion to clinical findings and profound lactic acidosis. This is associated with a high mortality [37].

If aortic dissection is suspected on the basis of clinical assessment, then diagnostic imaging should be performed. Choice of imaging technique depends on patient stability, local expertise and availability. A second imaging modality should be performed if the first imaging is negative but clinical suspicion remains high.

Once dissection is confirmed then initial management is aimed at limitation of propagation of the false lumen before a definitive management plan is instituted, (Figure 6).

In patients with MFS who have undergone aortic aneurysm repair, the ascending aorta is usually the site of the first operation, with mean age at time of surgery of 32.4 years. The majority have subsequent dissections or aneurysms, $95 \%$ of which are in other regions of the aorta. The presence of dissection at the time of first 


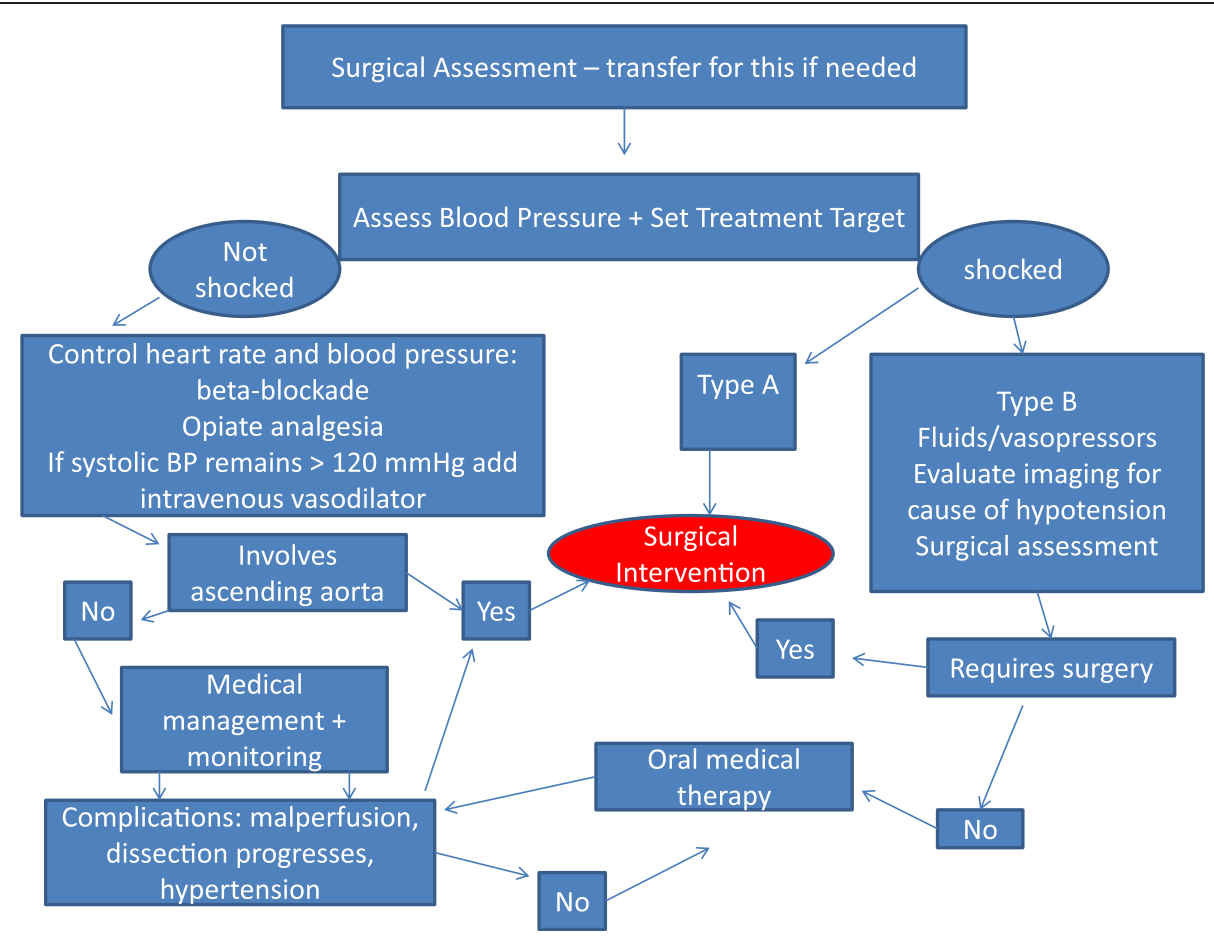

Figure 6 Management pathway for acute aortic dissection. Adapted from 2010 ACCF/AHA guidelines.

surgery is a significant predictor of requiring a second surgery [38]. In aortic dissection survivors with MFS, $80 \%$ have involvement of the ascending aorta, but about two thirds have involvement of the descending aorta or pure descending aortic dissection. Of those with dissection confined to the descending aorta, more than half have aortic root diameters less than $5 \mathrm{~cm}$. Just over half of all patients incur a further clinical event during follow-up, usually in the descending aorta [39]. Of relevance, it has been shown that patients who have undergone elective aortic root surgery have a greater distal aortic diameter [40].

Aneurysms of the pulmonary trunk in MFS are rare [41], although dilatation of the main pulmonary artery is relatively common, occurring in over $10 \%$ patients $[31,42]$.

\section{Valves}

Aortic, mitral and tricuspid valves can be involved in MFS. The incidence of mitral valve prolapse and mitral regurgitation increases steadily with age, (although severe forms of MFS which may present in the neonatal period are associated with severe mitral and tricuspid disease) [43]. A survey of young patients with MFS (mean age 11.9 years) found over two thirds to have echocardiographic features of mitral valve dysfunction, usually prolapse. More than $25 \%$ of the cohort had disease progression over the following 4-6 years. However surgery for mitral regurgitation alone is uncommon in adults. The severity of mitral regurgitation in adults is unrelated to gender, unlike the risk of aortic dilatation and its complications [32].
The mitral valve changes associated with MFS are different to those associated with classic myxomatous mitral disease and are present in up to $80 \%$ adult patients. In MFS the leaflets are longer and thinner with an increased prevalence of bileaflet and anterior leaflet prolapse. However, posterior leaflet prolapse remains the most common valvular abnormality. In a surgical study patients with MFS were less likely to receive mitral valve repair than replacement. However, out of those receiving repair, the results were excellent with $96 \%$ freedom from reoperation at 10 years [44].

When the tricuspid valve is affected in MFS, it is usually in combination with the mitral valve. Similar to the mitral valve the pathologic mechanism of regurgitation is prolapse and the valve may be suitable for repair [45].

Aortic valve dysfunction is felt to be a later occurrence, usually secondary to annular dilatation [31]. However, the aortic valve is more than just a passive structure sitting between the left ventricular outflow tract and the aortic root. This is an important functional unit subject to complex haemodynamic forces. The sinuses of Valsalva have a particularly important role in the valve's normal function.

As the aortic valve opens, the sinuses provide adequate space to prevent occlusion of the coronary artery orifices. In addition, this space permits the formation of eddy currents which hold the leaflets away from the aortic wall and facilitate appropriate valve closure at the end of systole. In diastole the sinuses move outwards and decrease the forces exerted on the valve leaflets. 
As the aortic root dilates, the valve commissures will be moved outwards, thereby reducing leaflet coaptation in diastole, but also impairing the ability of the aortic sinuses and valve to function as one unit, thereby accelerating valvular dysfunction [46].

\section{Myocardial involvement}

Fujiseki and colleagues reported the first case of MFSassociated myocardial involvement in 1984 [47]. Since then both right and left ventricular dysfunction and a dilated cardiomyopathy phenotype have been described [48]. Early studies using echocardiography found that a small proportion of patients had altered left ventricular dimensions [49]. Studies utilising more sensitive imaging techniques in those without valvular disease identified mild but significant impairment of left ventricular function [50]. Both systolic and diastolic impairment of function was identified by tissue doppler imaging (TDI). Importantly echocardiography was unable to identify any differences in left ventricular diameters, but CMR demonstrated a significant increase in end-systolic volume corrected for body surface area (BSA) and a decrease in ejection fraction. Left ventricular dilatation may predispose to alterations of repolarisation and fatal ventricular arrhythmias [51].

Biventricular involvement in MFS is well recognised. An echocardiographic study focusing on right ventricular systolic function found a reduction in the variables of TAPSE; rate of pressure rise $(\mathrm{dp} / \mathrm{dt})$ and peak TDI velocity of the basal lateral wall in those with MFS [52].

A comprehensive cardiac assessment was undertaken by Alpendurada et al. using cardiovascular magnetic resonance [53]. Evaluating patients with MFS and without cardiovascular surgery or significant valvular disease, $25 \%$ had a reduced left ventricular EF\%. Just over $10 \%$ patients also had reduced right ventricular EF\%. No patient with a normal LVEF\% had a reduced RVEF\%.

Although the degree of ventricular impairment in the vast majority of the patients featured in these imaging studies was mild, it is still early in the recognition of a 'MFS-associated cardiomyopathy'. The natural history of this entity will be almost impossible to separate from developing aortic and valvular pathology in this patient group, but most authors recognise opportunities for pharmacologic intervention in these patients.

In addition to cardiomyopathic changes, the impact of skeletal abnormalities in MFS should also be considered. Recent studies have demonstrated that pectus excavatum can reduce resting right ventricular function [30]. Surgical correction of this deformity may improve cardiac function [29].

\section{Criteria for aortic surgical intervention}

Just over a decade ago published surgical cohorts had a mean diameter of $6.8 \mathrm{~cm}$, which was a reflection of both varied surgical practice but also of late or missed diagnosis of MFS in this patient population [54]. However the increasing incidence of a poor outcome after emergency surgery versus the low mortality of less than $2 \%$ for elective aortic replacement was already recognised and increasing numbers of surgeons were performing prophylactic root replacement at a diameter of $5.5-6.0 \mathrm{~cm}$. Some groups in the late 1990's were proposing a further reduction of this value to 5.0 - $5.5 \mathrm{~cm}$ [54-56].

American and European guidelines published in 2010 advocate surgical repair of a dilated aortic root/ascending aorta when the external diameter is $5.0 \mathrm{~cm}[33,57]$. A summary and comparison of the guidelines is made in Table 4.

The American guidelines recognise the ongoing risk to the arch and descending aorta as sites for the later development of aneurysm formation and dissection, following prophylactic root repair. Routine lifelong imaging of the entire aorta is recommended. Whilst less data is available examining arch and descending aorta intervention, recommendations are made that in the presence of a chronic dissection, open repair of the descending thoracic aorta is undertaken at $>5.5 \mathrm{~cm}$. This is similar for the thoraco-abdominal aorta. Arch aneurysms are usually associated with disease of the adjacent proximal or distal aorta, and it is suggested that operative intervention in these individuals should be guided by the same parameters as for the adjacent segments.

Table 4 Surgical repair of aortic root/ascending aorta recommended

\begin{tabular}{|c|c|c|c|}
\hline \multicolumn{2}{|c|}{ American guidelines } & \multicolumn{2}{|c|}{ European guidelines } \\
\hline \multicolumn{2}{|c|}{ External diameter $>5.0 \mathrm{~cm}$} & \multicolumn{2}{|c|}{ External diameter $>5.0 \mathrm{~cm}$} \\
\hline Or at $<5.0 \mathrm{~cm}$ if: & Growth at greater $0.5 \mathrm{~cm} / \mathrm{yr}$ & Or at $4.6-5.0 \mathrm{~cm}$ if: & Dilatation at greater $0.2 \mathrm{~cm} / \mathrm{yr}$ \\
\hline Or & Family history dissection at $<5.0 \mathrm{~cm}$ & Or & Family history dissection \\
\hline Or & Presence of significant aortic regurgitation & Or & Severe aortic or mitral regurgitation \\
\hline Or in women contemplating pregnancy & $>4.0 \mathrm{~cm}$ & Or & Pregnancy is being planned ${ }^{\#}$ \\
\hline Also consider if: & Maximum CSA/height in metres $>10^{*}$ & In 'small' individuals use: & $\begin{array}{l}\text { Indexed diameter adjusted for BSA } \\
\text { of } 2.75 \mathrm{~cm} / \mathrm{m}^{2} \text { [58] }\end{array}$ \\
\hline
\end{tabular}

$\mathrm{CSA}=$ cross sectional area in $\mathrm{cm}^{2}$ of ascending aorta or root BSA = body surface area.

* Shorter patients have dissection at a smaller size. $15 \%$ patients with MFS have dissection at aortic root diameters less than $5.0 \mathrm{~cm}$

"Consider at 4.0-4.5 cm depending on serial growth on imaging and family history [59]. 
European guidelines also give attention to the risk of dissection elsewhere and patients should be considered for surgery when other parts of the aorta are greater than $5.0 \mathrm{~cm}$ or progressive dilatation is evident [57].

\section{Surgical intervention}

Surgery repairs or removes diseased tissue and structures, but alters the residual anatomy. Options for repair cover the spectrum from valve sparing root replacements to complete aortic valve, root and arch replacements, as well as other less invasive options. A basic understanding of the various surgical techniques is therefore important. This permits accurate and comprehensive reporting of pre and post operative images.

\section{The Bentall composite graft}

The first published description of the original valved graft conduit repair of the aorta was in 1968 by Bentall (Figure 7) [60]. The technique was developed to allow treatment of those patients with aortic root aneurysm or dissection in whom the proximal aortic rim was insufficient to allow the suturing of a tubular graft and preservation of the native coronary ostial anatomy. Instead, the tubular graft was sutured directly onto the ring of a Starr valve and this was inserted en bloc. Holes were then cut in the aortic prosthesis to allow reinsertion of the coronary arteries.

Originally the graft material was unsealed and had to be pre-clotted outside the patient. This changed as presealed material became available; then factory-made composite grafts and finally a revision of the coronary re-implantation technique with use of an aortic button [61]. As a consequence of increased operator experience and technical revisions the 30 day mortality from this operation fell to approximately $1.5 \%$ for elective cases

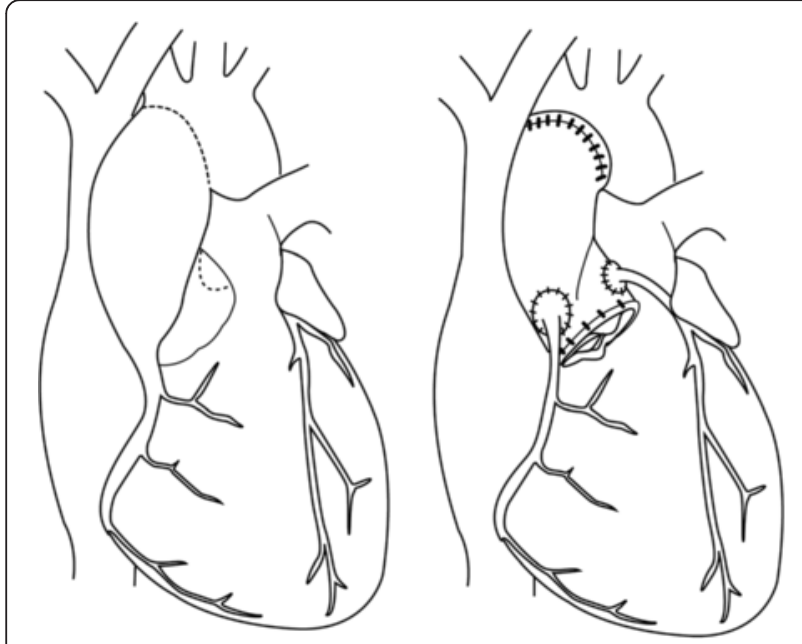

Figure 7 Bentall procedure.
[54,62]. However, rates for emergency repair remain significantly higher. 75\% 10 year survival is reported, yet concerns persist with regard to long-term thromboembolic risks and the need for ongoing anticoagulation in such a young patient cohort who remain at life-long risk of further dissection. Some have therefore tried to use total root replacement surgery using tissue valves [63].

\section{Valve-sparing procedures}

The aortic valve is a complex structure which cannot be matched by any prosthesis. The 3 cusps are more than passive sails, they interact with the root and LVOT. Aortic valve cusps are thin-walled pocket-like structures, yet strong and non-thrombogenic. The aortic root moves during cardiac cycle in a manner preceding and aiding opening and closing of AV [64-67]. Against this background valve-sparing root surgery was developed.

First Yacoub, then David proposed valve-sparing surgery $[68,69]$ using variations of root replacement by an artificial graft with preservation of the patient's native aortic valve.

In both, the sinuses of valsalva are resected first and a 3-4 mm rim of tissue to both sides of all commissures and along the attachment line of the cusps and coronary ostiae is left. The aortic root is replaced by a graft. The valve is then reimplanted into the vascular graft using a form of David technique or: can be remodelled into it as per the Yacoub technique (Figure 8).

In the Yacoub remodelling technique the graft first needs to be incised at its base so that the 3 commissures of the valve can be sewn into the 3 'tongues' of the graft. Hence pseudo-sinuses are created within the vascular graft. The sinuses within the aortic root are considered important for aortic valve function and coronary perfusion. Finally the coronary ostiae have to be reimplanted into the graft.

In the original David re-implantation technique the vascular graft is placed over the native aortic valve and secured below the aortic valve attachment. Then the aortic valve and commissures are secured within the graft. As a result the valve sits within the tubular graft without the formation of pseudosinuses. Again the coronary ostiae have to be reimplanted.

The results of the original David procedure are generally considered to be better than with the Yacoub procedure in MFS. This may be related to the restricted movement and reduced distensibility caused by the original David procedure. It is also hypothesised that the graft incisions in the Yacoub procedure might limit the ability of the graft to reduce further annular dilatation in MFS [70]. This remains the case even with additional annuloplasty.

The David technique has been revised several times and forms of version $\mathrm{V}$ are currently in use [71]. This retains the implantation of the valve within the graft, but 


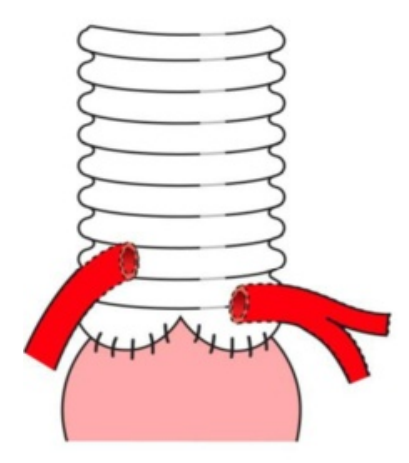

Valve sparing

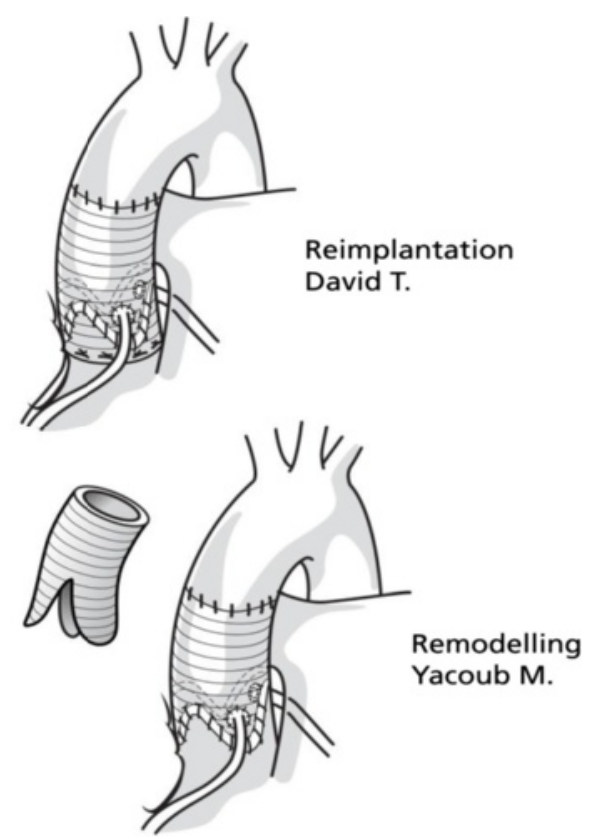

Figure 8 The David and Yacoub valve-sparing techniques for aortic root replacement.

additionally allows the creation of Dacron pseudosinuses. Interestingly, time-resolved $3 \mathrm{D} \mathrm{MR}$ velocity mapping can demonstrate formation of coronary cusp vortices post David repair, even in the absence of pseudosinus formation [72].

\section{Valve - sparing versus non valve-sparing surgery}

A recent systematic review of the surgical management of aortic disease in MFS compared the results of total root replacement (TRR) versus valve-sparing aortic root replacement (VSRR) [73]. The longer established TRR had been performed in the majority with a mean follow-up of 8 years; for VSRR the figure was 4.7 years. VSRR was associated with a fourfold increased rate of reintervention on the aortic valve (1.3\% per year vs $0.3 \%)$; with reintervention most likely in those undergoing remodelling of the root (Yacoub technique). On the other hand, TRR was associated with a significantly higher rate of thromboembolism $(0.7 \%$ per year versus $0.3 \%$ per year). There was no difference between the two techniques in the composite valverelated event. However, durability data for VSRR are still lacking and further registry data are awaited.

Both the American and European guidelines advocate the use of valve-sparing operations with root replacement in cases in which the aortic valve is anatomically normal and in high-volume centres. Only if valve-sparing surgery is not possible then root replacement with a valved graft conduit is advocated. However, caution is expressed with regard to long-term durability of residual aortic valve function and in this context the American guidelines recommend a reimplantation technique rather than remodelling.

\section{External aortic root support}

A further surgical technique has been pioneered and evaluated by NICE in 2011 [74]. An individualised external aortic root support (EARS) is used to reinforce the ascending aorta while leaving the native aortic valve intact and conserving the blood/endothelium interface [61]. Robicsek suggested many years ago that wrapping the aorta externally could prevent expansion. However the results of this early operation have not been good [75]. Furthermore, in the context of an already dilated aorta, the compromise of a hand-tailored external support at a time when "off the shelf" composite valve conduits were becoming available was worrying and not adopted in the main [54]. However, modern imaging and engineering methods have allowed us to revisit that idea. The recent development is born of the motivation, skill and creativity of a biomedical engineer with MFS who was the first individual to undergo this procedure just over 7 years ago. The clinical results for the first twenty patients were published in 2010 [76]. Each patient underwent CMR study of the aorta (more recently Cardiac CT has also been used) to provide digital information to produce a $3 \mathrm{D}$ reconstruction of the aorta from the aortoventricular junction to beyond the brachiocephalic artery using dedicated computer-aided design software. This was transformed into a thermoplastic model formed exactly to the physical model of the patient's aorta. The latter was then used as the frame upon which the bespoke external aortic support was manufactured from a medical grade polymer mesh (Figures 9 and 10). At surgery, without the need for bypass, the aorta was dissected away from 


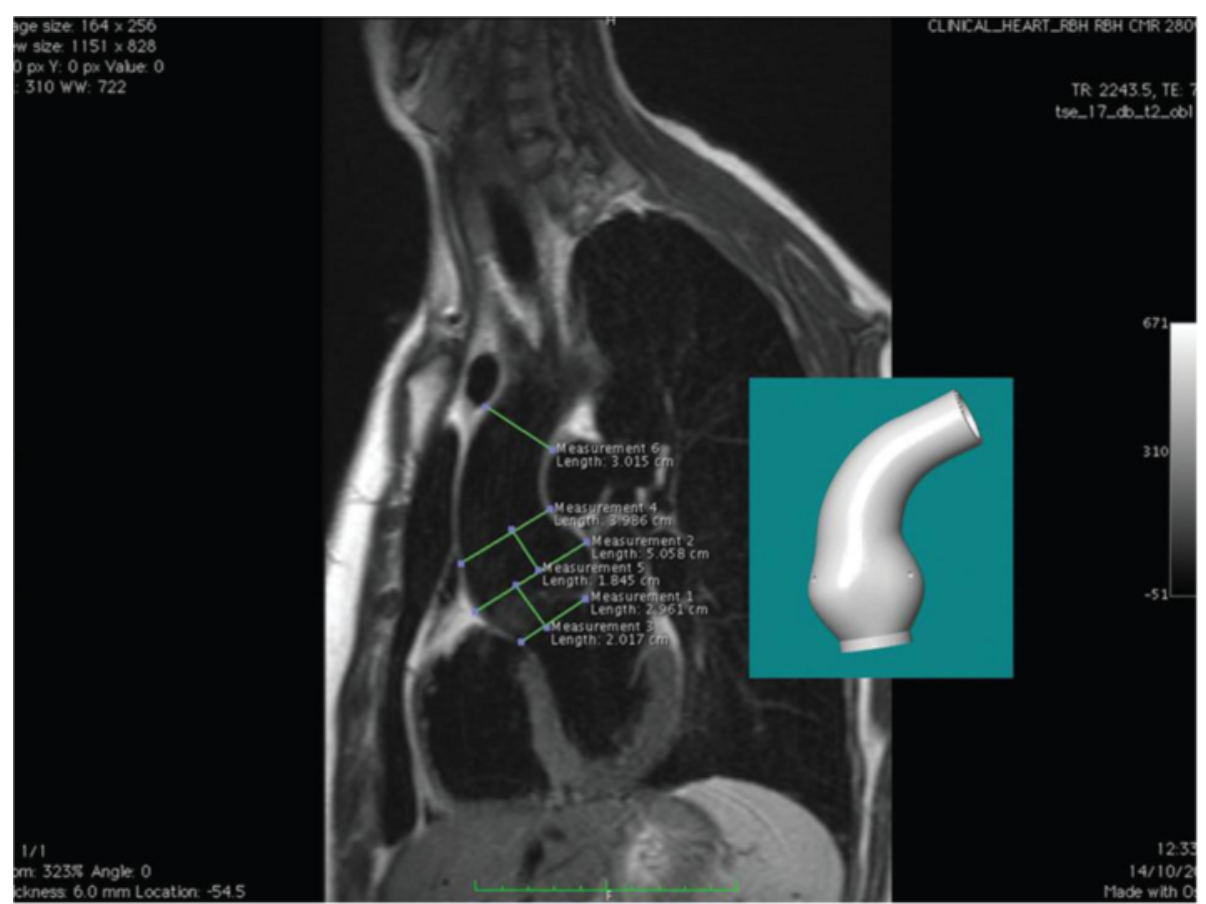

Figure 9 Example of black blood aortic CMR imaging, some of the measurements and the model made by computer aided design. Reproduced from the Journal Royal Society of Medicine 2010:103:370-375 [76].

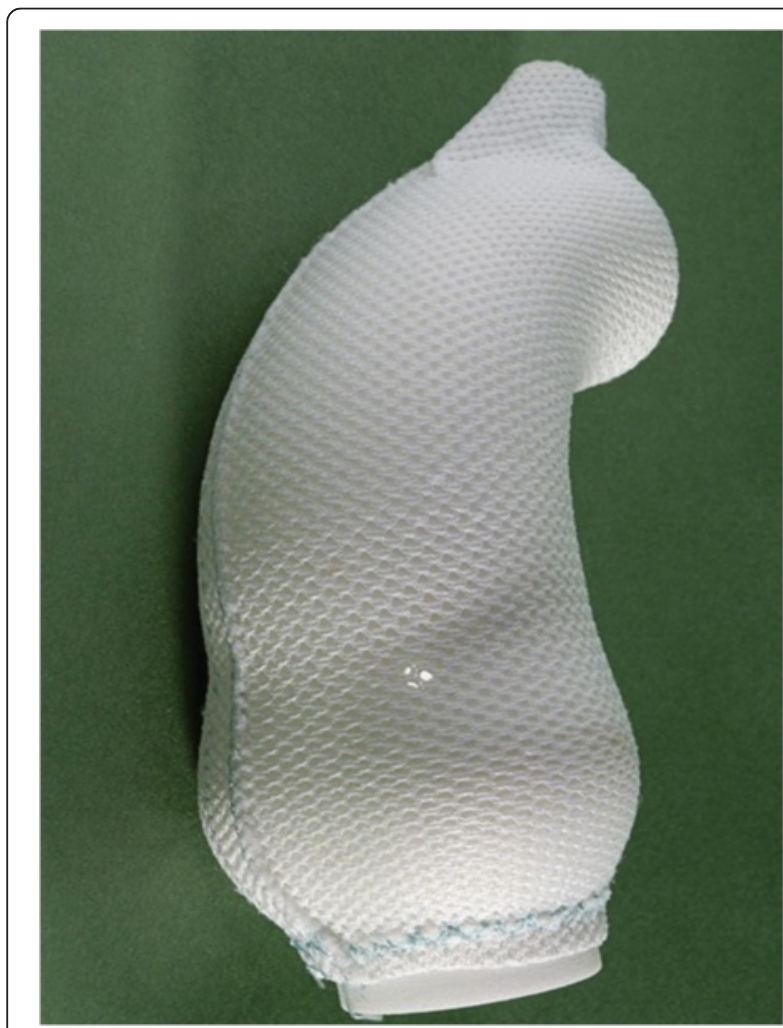

Figure 10 The aortic model covered with the external aortic root support made from a medical grade polymer mesh. adjacent structures before being encircled by the external support. The external support was secured without any direct incision or suturing of aortic tissue. Whilst current follow-up data is very hopeful for long-term outcomes, should surgery be required on any part of the aorta in future in these patients, the avoidance of anticoagulation will be of benefit [77]. This approach has a number of potential advantages over standard treatment for Marfan Syndrome:

1. External support may reduce mechanical stress on the aortic wall, thus reducing repetitive mechanical injury due to the pulse wave and retarding the degenerative process.

2. The operation can be performed without the need for cardiopulmonary bypass, myocardial ischaemia or circulatory arrest.

3. It avoids replacing the aortic valve and therefore life-long anticoagulation

NICE recognise that at the present time the outcome data is based on a relatively small number of patients and further data with regards to long term outcomes is awaited. Hence this procedure is undertaken by specialist teams only with collection of audit and clinical data.

\section{Endovascular stent grafting}

Endovascular stent grafting has been used in a few cases, however, long-term data are lacking and there are concerns 
about the ability of fragile aortic tissue to withstand the pressure of the stent over a long time. Such an approach should only be considered if the risks of open repair are prohibitive $[57,78]$. Aortic surgery has also been successfully combined with cardiac transplantation or left ventricular assist device implantation in patients with MFS $[79,80]$.

\section{Cardiac imaging}

With the ever growing appreciation of the complex manifestations of MFS, it has become apparent that patients need assessment of the entire aorta and careful study of valves and biventricular function [81]. As the number and quality of available imaging modalities has increased, it should have become ever easier to provide this imaging. However, a review of the literature reveals a heterogeneity of approaches and intermodality validation based on techniques or views which may not be routinely used. It is worth reviewing the current guidelines before reviewing each imaging modality individually, with an emphasis on cardiovascular MR (CMR).

\section{Imaging guidelines}

The European guidelines recommend using 2 modalities in each patient and make recommendations for both diagnostic and follow-up imaging [57] (Table 5).

American guidelines also recommend a TTE is performed at diagnosis to establish aortic dimensions, ventricular and valvular function, however, it should be repeated at 6 months to establish the rate of change of aortic parameters. If there is no significant change then annual TTE will suffice. If however there is significant aortic expansion or the initial aortic diameter is $>4.5 \mathrm{~cm}$, then more frequent imaging is advised. The guidelines recognise that most patients with MFS also undergo X-ray computed

Table 5 European guidelines for imaging in MFS

\begin{tabular}{ll}
\hline Diagnostic & Follow-up \\
\hline $\begin{array}{l}\text { TTE of aortic root: measure at annulus, } \\
\text { sinuses of Valsalva, sinotubular }\end{array}$ & TTE an annual basis if stable \\
junction and distal ascending aorta. & \\
$\begin{array}{ll}\text { TTE of left ventricular and } \\
\text { valvular function. }\end{array}$ \\
$\begin{array}{ll}\text { Either CMR or CT of entire aorta * } & \begin{array}{l}\text { CMR or CT of entire aorta: every } \\
5 \text { yr if normal aortic dimensions } \\
\text { beyond root; at least annually if } \\
\text { aneurysm formation beyond root. }\end{array}\end{array}$
\end{tabular}

\section{Avoid coronary angiography due to increased dissection risk}

$\mathrm{CT}$ coronary angiography pre-op

to assess for coronary disease

where possible

TOE- only in assessment of

suspected aortic dissection

${ }^{*}$ CMR assessment of aortic wall biophysical properties may be possible - see CMR section below. tomography (CT) or CMR but they do not give any specific guidance in this respect. They note that measurements made on these modalities are $2-4 \mathrm{~mm}$ greater than those on TTE, but it is on these external diameter measurements that surgical intervention is usually planned. TOE is again reserved for the setting of dissection.

Following surgical repair of the aortic root or ascending aorta, lifetime imaging of the entire aorta is recommended, in line with the European position.

Specific consideration is given to women with MFS during pregnancy and monthly or bimonthly echo is recommended in those with aortic root or ascending aortic dilatation. If the more distal aorta is affected then CMR without gadolinium may be used for monitoring during pregnancy.

The American guidelines address more than just the choice and timing of modality. They stress the importance of the comprehensive and reproducible nature of reporting of aortic disease which is key in MFS. An aneurysm is defined as: 'a permanent localised dilatation of an artery, having at least a 50\% increase compared with the expected normal diameter of the artery in question.' The term 'ectasia' refers to lesser degrees of arterial dilatation.

Analysis of aortic images should be undertaken at a workstation which permits rotation of the acquired images to review each segment of the aorta and its branches. Reports should contain essential elements and measurements of aortic diameter should be taken at reproducible landmarks, perpendicular to the longitudinal or flow axis of the vessel (Figure 11). Diameter measurements from axial images are highlighted as being inherently incorrect unless properly aligned.

Recognition of the detailed analysis required to produce robust reports is welcomed by imagers. This is in keeping with SCMR guidance on analysis of thoracic magnetic resonance angiography and the multiple sequences which may be required for a comprehensive study of the aorta [82]. SCMR also recognises the need for timely reporting which will be influenced by clinical urgency, but ideally within 24 hours of a routine scan a finalised report should be available. As a minimum SCMR recommends measurement at the aortic annulus; sinuses of Valsalva, sinotubular junction and ascending and descending diameters at the level of the pulmonary artery. It is also recommended to report, when present: sinotubular effacement, tortuousity, aortic aneurysm and aortic dissection [83]. An aneurysm should be described in terms of size, morphology, location, mural thrombus, local effects on surrounding structures, post contrast appearance (if contrast given) and any pericardial, pleural, mediastinal or periaortic fluid. A similar level of detail is required for description of a dissection (either Stanford or De Bakey classification is acceptable) including the location of the tear 

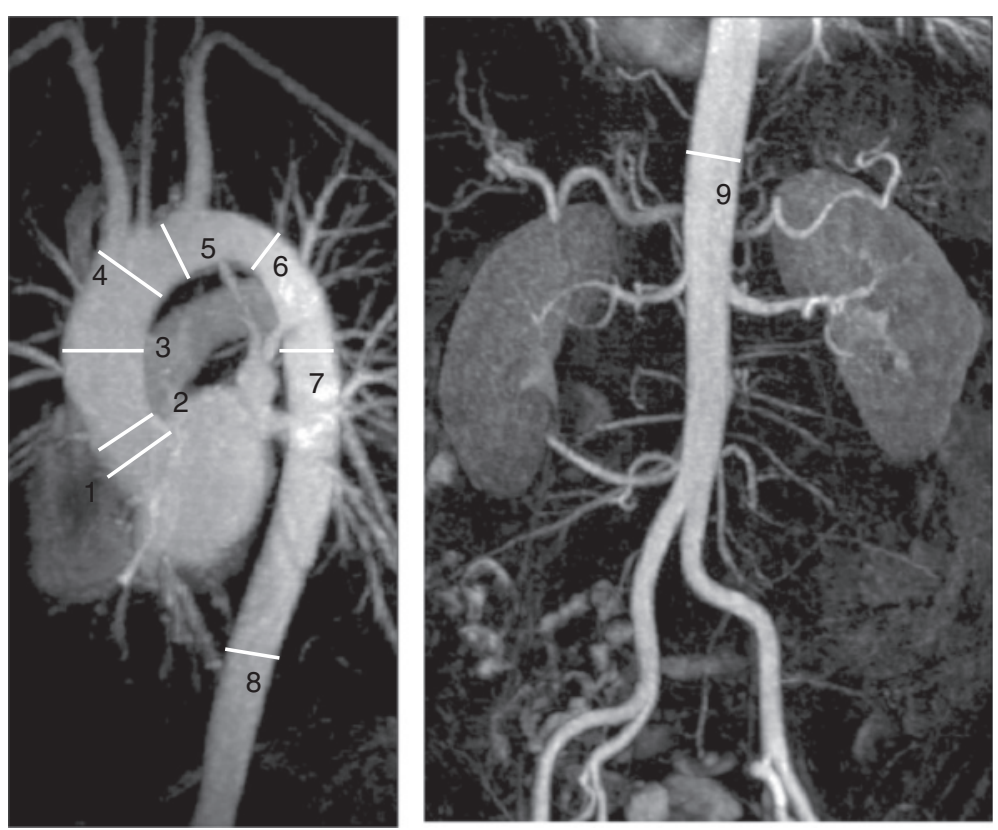

Figure $11 \mathrm{CMR}$ aorta demonstrating standard imaging landmarks for the thoracoabdominal aorta advocated by guidelines. 1: Aortic sinuses of Valsalva 2: Sinotubular junction 3: Mid ascending aorta 4: Proximal aortic arch (at origin of inominate artery) 5: Mid aortic arch (between left common carotid and subclavian arteries) 6: Proximal descending thoracic aorta (approx $2 \mathrm{~cm}$ distal to left subclavian artery) 7: Mid descending aorta 8: Aorta at diaphragm ( $2 \mathrm{~cm}$ above origin of coeliac axis) 9: Abdominal aorta at origin of coeliac axis.

or evident communication and whether an intimal flap is visible.

The American guidelines for CT and CMR recommend that the external aortic diameter should be measured and at the root the widest diameter, usually at mid-sinus level, should be taken. The latter also applies in echo but here the internal diameter should be measured [33]. However the rationale for this is that lumen size may not accurately reflect external diameter in the setting of mural thrombus, intramural haemtoma, thrombosed false aneurysm and aortic inflammation. Yet in the setting of normal aortic wall thickness, measuring external diameter will add a few millimeters $(\sim 3-4 \mathrm{~mm})$ to the size of the aorta compared with the internal diameter measurements which may have impact on the timing of surgery/intervention. Furthermore, this will be at disparity with the echo measurement. In addition, most of the data and cutoff values used for surgical intervention are based on echo internal diameter measurements. Indeed, the guidelines state that Marfan aorta of more than $5 \mathrm{~cm}$ is at risk but avoids saying whether that's internal or an external diameter.

In our centres we are still using internal aortic diameter measurements but are vigilant for any abnormal aortic wall pathology (e.g. intramural haematoma, dissection, ulceration, aortitis, etc.) and describe these lesions with measurements separately in the CMR/CT reports to address the guidelines' concerns. We also have lots of patients who have been followed up for years using internal diameter measurements and as a group (imagers and surgeons), we felt that it is important to have continuity in these measurements.

In essence, to minimize errors, it is important that when following up patients for changes in aortic dimensions that measurements should be done at a reproducible anatomical plane perpendicular to the axis of flow and any abnormality of the aortic wall described and measured. When possible measurements should be indexed to body surface area.

Radiation exposure should be minimised wherever possible. Invasive angiography is no longer considered as a first-line investigation for aortic diseases and is rarely used in this setting.

\section{Imaging modalities \\ Echocardiography}

The portability, safety and cost-effectiveness of TTE have facilitated its fundamental role in both the diagnosis and monitoring of the aortic root in those with MFS. $\mathrm{M}$-mode recordings were used to establish the effect of propranolol on the aortic root [19]. Recent studies have also used M-mode interchangeably with 2D-images to assess aortic root size [59]. Subsequent work has been undertaken which validates 'inner edge to inner edge' measurements of the proximal aorta against TOE [84] and TTE forms an integral part of most imaging guidelines in 
MFS. Yet a review of the literature demonstrates variability in the approach to TTE root measurement [85].

Yet the strength of TTE is that it may also assess valvular and biventricular function in both adults and children. As our understanding of MFS has grown, the assessment and monitoring of biventricular function per se should be part of our assessment, with tissue doppler imaging incorporated into any protocol used, although this has yet to feature explicitly in guidelines [86]. Chest wall deformities preclude adequate imaging in only the minority of patients with MFS.

TOE is used mainly in the setting of suspected acute aortic root dissection in MFS. In experienced hands it has a sensitivity and specificity comparable to CT and CMR [87]. The echocardiographic diagnosis of dissection requires demonstration of a dissection flap separating true and false lumens. There may be more than one intimal tear present and colour Doppler may be used to show differential flow on either side of a flap. The true lumen usually expands during systole and collapses during diastole with forward flow during systole. A false lumen shows the reverse expansion pattern, accompanied by reversed, delayed or absent flow. Spontaneous contrast may be present. Assessment of aortic valve competency, presence of pericardial effusion and involvement of the coronary ostia may help guide surgical intervention. Increasingly intra-operative TOE is being used for assessment and monitoring. However, as a semi-invasive procedure which has the potential to raise a patient's blood pressure, it is not used for routine aortic surveillance (Figure 12).

\section{X-ray computed tomography (CT)}

$\mathrm{CT}$ is one of the longest serving imaging modalities in the assessment of aortic disease. It is a rapid test which can be used in either the acute or chronic disease setting to evaluate the entire aorta and periaortic structures. It can distinguish between acute aortic syndromes and elucidate branch vessel involvement. With the advent of ECG-gating, the risks of motion-artefact mimicking dissection have been greatly reduced. International Registry data have previously shown CT to be the first-line investigation in acute dissection in $61 \%$ cases [88]. Sensitivities of up to $100 \%$ and specificities of $92-100 \%$ for helical CT have been reported in this setting [87]. A noncontrast study to look for intramural haematoma, followed by a contrast study to identify a dissection flap and the contrast extravasation of rupture is recommended [33]. The vascular tree from neck to pelvis can be rapidly imaged to provide valuable information to the referring team and it is possible to obtain a CT coronary angiogram and aortogram in one ECG-gated CT acquisition. CT features which discriminate between the true and false lumen have been described [89]. Axial measurements tend to overestimate the thoracic aortic diameter and measurements planned from double-oblique images are preferred [90]. Recommendations on technical parameters for acquisition and reconstruction are available [33].

Where used pre-operatively, cardiac CT offers the ability to perform a complete evaluation of the thorax. In patients with MFS this has the advantage of assessing the chest wall and surgical access with particular reference to coronary artery position, in those with chest wall deformities [91].

With the expansion in cardiac CT angiography, attempts have been made to evaluate its performance in valvular disease. A recent retrospective study comparing CT with TTE calculated a 96\% sensitivity and 93\% sensitivity for the diagnosis of mitral valve prolapse. However, it should be noted that this required retrospective gating to acquire the dataset and hence radiation exposure ranged from 7-11 mSv between patients. However, when retrospective gating has been required for other reasons,

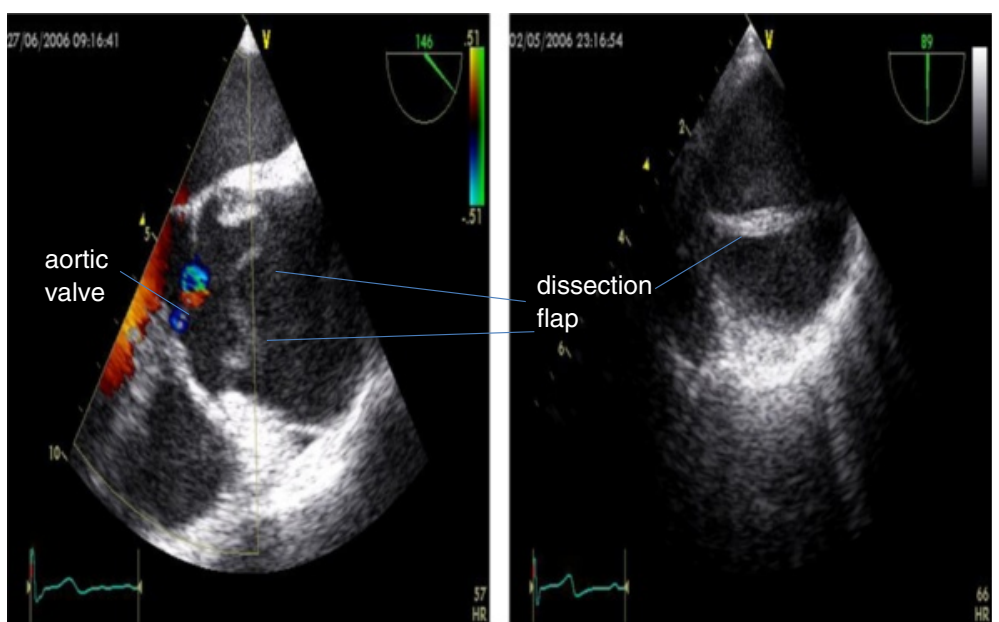

Figure 12 a) Dilated aortic root on transoesophageal echo with evidence of dissection flap b) Transaxial view of aortic dissection. 
it may be worth looking at the dataset not only for MVP but also for an assessment of aortic valvular and left ventricular function. Currently there are limitations in the ability of CT to grade valvular dysfunction [92]. However on mid-systolic images the tethered appearance of the aortic valve resulting from sinus of Valsalva dilatation and a triangular coaptation defect may be present in enddiastole if aortic regurgitation is present [93].

The ability of CT to demonstrate and assess vasculature is not in doubt and, in the acute setting it can allow rapid diagnostic imaging assessment of an unwell patient. However, it is a technique involving the use of ionising radiation. Therefore it is not ideally suited for long term follow up, particularly in a young patient cohort whose lifetime accumulated dose could be considerable. ECG-gated low-voltage techniques significantly reduce ionising radiation exposure and minimise potential long-term harm [94].

\section{Aortography/angiography}

Aortography was first used in the 1960s as a method for assessing aortic dissection. However it is invasive, requires the use of iodinated contrast and radiation. Whilst in the setting of primary PCI it is still possible to find oneself diagnosing acute aortic dissection by this method, it is otherwise rarely used and is not advocated in the setting of MFS.

\section{Cardiovascular magnetic resonance (CMR)}

\section{Advantages and limitations}

CMR is not limited by acoustic windows and is free from ionising radiation. The entire aorta can be imaged and complications including aneurysm formation, dissection, and previous surgery are well visualised. This makes it ideal for long-term follow up of patients.

Anatomical information can be gained, including origin and exit of intimal tears. CMR has equivalent sensitivity and specificity to CT for diagnosis of suspected thoracic aortic dissection, but is more accurate when the pre-test probability of dissection is high [87]. It has been validated against echocardiography for aortic root measurement and is well recognised as being superior at demonstrating the asymmetrical root dilatation which is often seen in MFS [95].

CMR allows assessment of both global and regional biventricular function and allows visualisation of the consequences of valvular dysfunction. Blood flow can be assessed in both normal and abnormal vessels. Reconstructions in 3 dimensions are a powerful tool for demonstrating anatomy to colleagues and patients alike. Utilising various sequences this technique is unsurpassed at characterising vascular and myocardial tissue.

The requirement for breath-holding limits the use of CMR in the unstable patient; however, availability and expertise are increasingly enabling studies to be tailored to the individual patient.

\section{Proposed CMR protocol}

We offer the following CMR protocol for imaging a patient with MFS in the pre-operative setting, (Figure 13).

\section{Protocol note: aortic distensibility assessment}

High-resolution cine imaging in a plane perpendicular to the ascending and/or descending aorta allows measurement of aortic cross-sectional area during systole and diastole. Measurement of regional aortic distensibility by CMR is calculated from the change in volume of an aortic segment and from aortic pulse pressure estimated by a sphygmomanometer at the level of the brachial artery. The lumen of the aorta is outlined manually on the computer screen to measure the change in aortic area $(\Delta \mathrm{A})$ between diastole and systole. Aortic distensibility can be derived from the change in volume ( $\Delta V=\Delta A \times$ slice thickness) of the aortic segment divided by the aortic pulse pressure $(\Delta P)$ measured by a sphygmomanometer [96]. Automatic measurement of aortic cross-sectional area is also possible [97].

$$
\begin{aligned}
\text { Aortic distensibility } & =(\text { Amax }- \text { Amin }) / \text { Amin } \\
\times \text { pulse pressure } & \\
\text { Amax } & =\text { maximal aortic area } \mathrm{mm}^{2}, \\
\text { Amin } & =\text { minimum aortic area } \mathrm{mm}^{2}, \\
\text { Pulse pressure } & =\text { systolic }- \text { diastolic blood pressure }
\end{aligned}
$$$$
\text { ( } \mathrm{mmHg}) \text {. }
$$

The accuracy of the indirect measurement of the pressure change needed to compute distensibility is limited as it ignores the changes in the pressure wave as it propagates through the arterial tree (a process known as amplification). Further, it is important to obtain this pressure data on patients ideally lying in the CMR scanner using CMR compatible apparatus. Despite the limitations of the pressure measurement, there is a good correlation between measurement of local aortic compliance and measurement of global compliance from the speed of the propagation of the flow wave within the vessel [98].

Flow wave velocity is defined as the speed with which a flow wave propagates along a vessel and is regarded as the purest measure of arterial stiffness. It is the quotient of distance travelled divided by the time taken for the flow wave to move between the two points and represents an average for that length of vessel. The approach is dependent on assessment of path-length travelled and accurate measurement of pulse arrival time. The latter requires recognition of equivalent features or points on leading edges of the proximal and distal flow waveforms, a process made complicated by alterations that occur in flow wave morphology and magnitude as it progresses down the vessel. Unlike non-invasive measurements relying on linear, transcutaneous measurements, CMR makes 


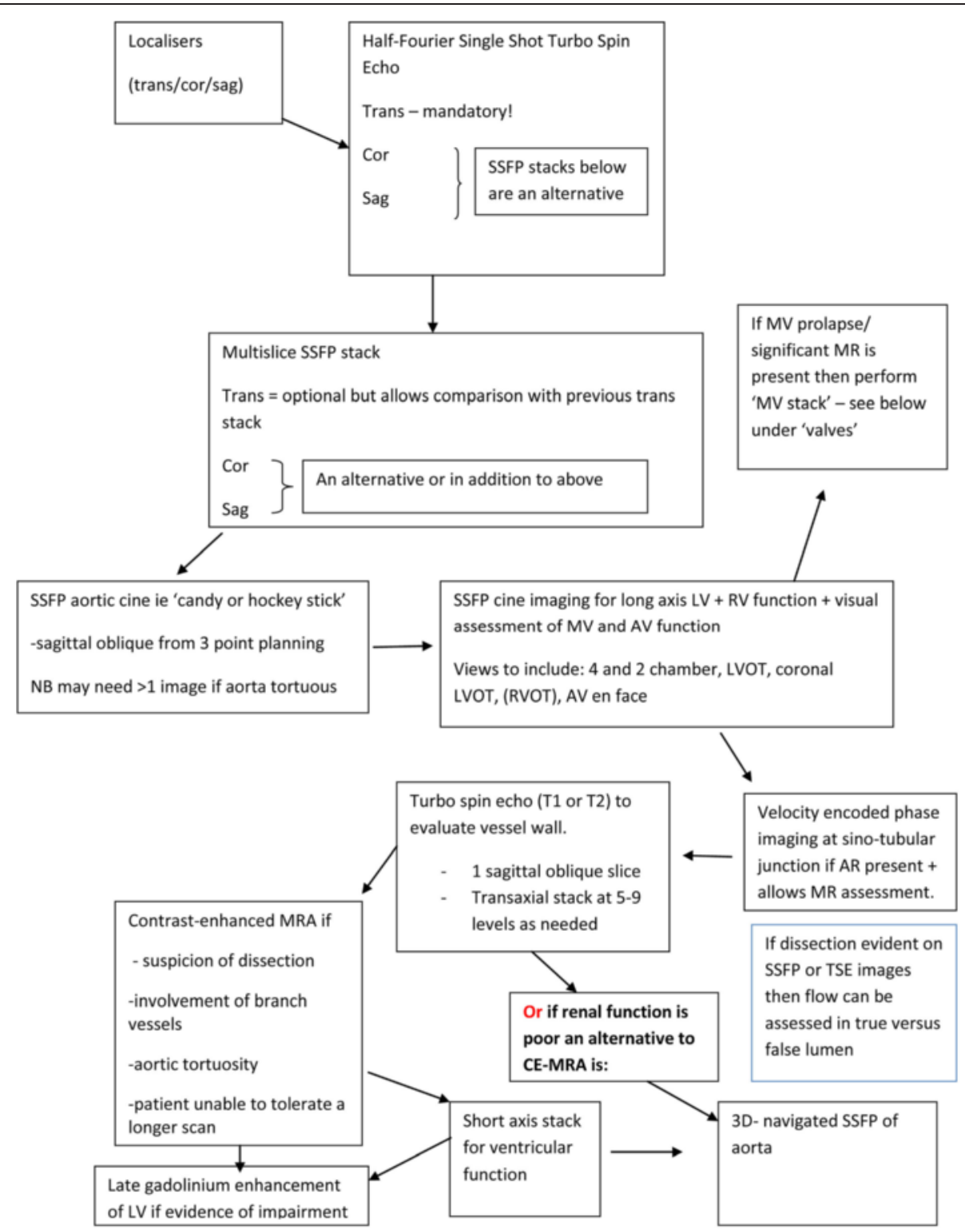

Figure 13 CMR protocol. Key to protocol abbreviations: trans = transaxial; cor = coronal; sag = sagittal; MV = mitral valve; $A V=a o r t i c$ valve; MRA = magnetic resonance angiography; TSE = turbo spin echo. Typical Imaging Parameters and points to note: Aortic SSFP- FoV Read $320 \mathrm{~mm}$, slice thickness $7 \mathrm{~mm}$, flip angle $80^{\circ}$, voxel size $1.7 \times 1.7 \times 7.0 \mathrm{~mm}$. TSE $-5-10$ parallel images planned from a transverse stack along long axis of aorta. Image position can be copied from Half-Fourier Single Shot TSE or SSFP stacks. For T2 weighted TSE: FoV Read 340 mm, slice thickness 6.0 mm, TR 700 ms, TE 81.0 ms. For T1 weighted TSE: FoV Read 340 mm, slice thickness 6.0 mm, TR 750 ms, TE 31.0 ms. CE-MRA- Give 0.1-0.2 mmol/kg gadolinium. Images should be reconstructed in MPR and analysed in thin MIP. 3D Navigated SSFP MRA- FoV Read $320 \mathrm{~mm}$, slice thickness $1.5 \mathrm{~mm}$, flip angle $90^{\circ}$, voxel size $1.0 \times 1.0 \times 1.5 \mathrm{~mm}$.

no assumptions about the shape of the artery and can accurately measure the path-length travelled.

\section{Follow-up studies}

What is most important in assessment of the aorta is accuracy and reproducibility. These patients are attending for lifelong follow-up and variation in measurement techniques could have disastrous consequences.
In CMR there is a surprising lack of standardisation of methodologies. In part this stems from the flexibility of the technique, with multiple types of sequences offering the ability to derive information about the aorta. For example, ECG-gated end-diastolic black-blood images using spin echo can be used to assess anatomy and morphology; SSFP-based cine images can be used to do the same. Contrast-enhanced MRA may be used but this is usually 
done without ECG-gating and there is a risk of motion artefact, particularly in the aortic root.

With such a wide choice available one should be aware of the advantages, limitations and differences between the sequences and the measuring planes. In recent years a body of work has been undertaken to investigate this further.

Measurements of the aortic root can reliably be obtained from SSFP-based cine images. Sinus of valsalva planes can be planned from oblique sagittal and oblique coronal LVOT planes. Sinus-sinus and sinus-commissure measurements taken at end-diastole are most comparable with echo and reference values are available (Figure 14) [99], It is important to quote the maximum trans-sinuses measurement which is usually the sinus-sinus measurement in the report.

It is well recognised that aortic size can be significantly overestimated by axial measurements when compared with orthogonal measurements when the aorta is not straight and the axial plane is not perpendicular to the true axis of the aorta. This could affect management decisions in up to $13 \%$ patients and has led some investigators to advocate the use of contrast-enhanced magnetic resonance angiography (CE-MRA) in patients, where possible with ECGgating to minimise aortic root motion-induced artefacts. However, this appears to be rarely done in clinical practice [100]. When CE-MRA is used, careful reconstruction of images is required. Unfortunately without ECG-gating it is the root measurements which are the least reliable, but normal values have been generated for various patient groups [101].
In response to concerns about regularly performing CE-MRA with gadolinium in patients, a non contrastenhanced MRA using 3D-navigated SSFP has been trialled [102]. Although it has had some success, it is susceptible to arrhythmia and adds approximately 10 minutes to the scan time. Comparison of 3D-navigated SSFP with CEMRA, 2D T2 black blood (BB) and 2D SSFP-based cines has been reported. [103] 3D-navigated SSFP and CE-MRA provide the largest aortic measurements and $\mathrm{T} 2 \mathrm{BB}$ the smallest. $\mathrm{T} 2 \mathrm{BB}$ has the best inter-observer variability but all sequences have an inter-observer variability of $>0.9$. Vessel wall analysis is optimal on T2 BB images. 3Dnavigated SSFP measurements correlated best with the gold standard of ECG-gated CT, but the images are less sensitive for demonstrating dissection flaps when compared with CE-MRA.

It is reasonable to derive from these studies that several sequences should be used to assess the aorta in patients with MFS. Our 'basic' T2 BB and 2D SSFP sequences can produce beautiful images from which extremely detailed and reliable measurements can be made [104]. However CE-MRA can be of particular use when assessing a tortuous aorta and navigated 3D-SSFP may be used in those in whom renal impairment is an issue.

\section{Clinical application}

The following sections contain examples of black blood, SSFP and CE-MRA images used in clinical context.
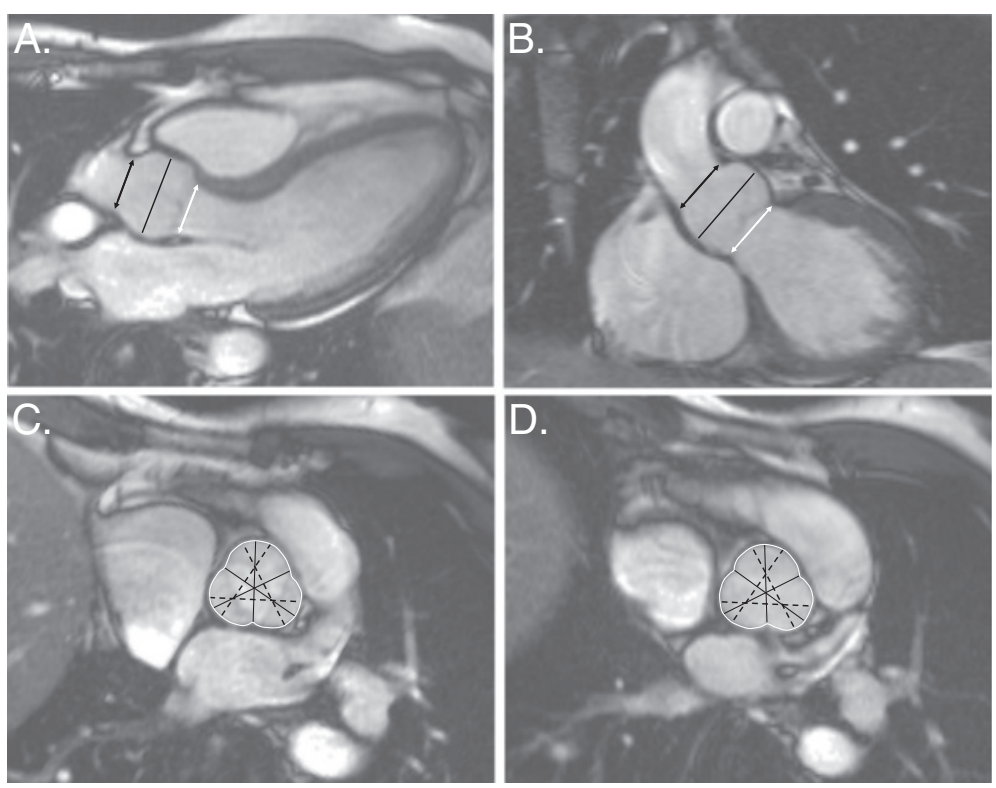

Figure 14 SSFP-based imaging. A, An oblique sagittal LVOT cine at end diastole showing the levels of annulus, sinus, and sinotubular junction measurements (white arrow, black line, and black arrow, respectively). B, An oblique coronal LVOT cine showing the equivalent levels of measurement. C, A systolic sinus plane image, showing 3 cusp-commissure and 3 cusp-cusp lines of measurement (continuous and dashed black lines, respectively) with the cross-sectional area outlined in white. D, An end diastolic sinus plane image, showing the cusp-commissure and cusp-cusp lines of measurement. Reproduced with permission [99]. 


\section{Aorta and branches}

A description of the classification of aortic dissection and complications is given in the section on the aorta. Figure 15 demonstrates aneurysmal involvement of the subclavian arteries in a patient who has undergone previous surgery. Figure 16 demonstrates black blood imaging of a type A dissection and Figure 17 demonstrates postoperative SSFP imaging of a dissection which involved the ascending aorta, but also the head and neck vessels with a visible flap in the proximal descending aorta.

\section{Valves}

Whilst the primary purpose of CMR in MFS is usually aortic assessment, it is also capable of providing useful information on valvular function. SSFP-based cine imaging in an LVOT view can reliably detect mitral valve prolapse [105]. The anatomical basis for regurgitation can then be investigated by performing a mitral valve stack. This is a contiguous stack of $5 \mathrm{~mm}$ slices aligned with MV inflow and cutting through the major line of coaptation. It should move from the superior to inferior commissure in the LVOT view. In this way the scallops of both leaflets may be demonstrated. Any regurgitation may be quantified:

\section{Mitral regurgitant volume}

$=\mathrm{LV}$ stroke volume - aortic forward flow

$(\mathrm{ml} /$ cardiac cycle fromaortic flow analysis at level of the STJ)

\section{Regurgitant fraction \\ $=$ regurgitant volume $/ \mathrm{LV}$ stroke volume $\times 100 \%$}

The aortic valve should be assessed well by a standard CMR protocol. The LVOT and coronal LVOT SSFP- based cines will demonstrate AR as a signal void. The 'en face' AV view planned from the LVOT views will demonstrate abnormal cusp morphology or defects in coaptation. However cine images alone should never be used to quantify any degree of regurgitation.

Through-plane velocity flow mapping at the STJ should be performed to quantitatively assess AR.

Aortic regurgitant volume in $\mathrm{ml} /$ cardiac cycle is the reverse flow from analysis of flow mapping.

$$
\begin{aligned}
& \text { Regurgitant fraction } \\
& =\text { regurgitant volume/aortic forward flow in } \\
& \text { systole } \times 100 \%
\end{aligned}
$$

This method will underestimate the degree of AR since the slice is at the level of the ST-J and does not account for annular motion and coronary perfusion during the cardiac cycle (see Figures 18,19 and 20).

\section{Cardiomyopathy/Assessment of ventricular function and volumes}

CMR is the gold standard for biventricular assessment and can detect the mild 'DCM phenotype' of MFS cardiomyopathy (see myocardial involvement in MFS). Several CMR software packages allow rapid analysis of biventricular volumes and function. If a more focused approach is required clinically then LV analysis can be performed. If LVEF is abnormal, in the absence of valvular dysfunction or other aetiology, then RV analysis should be performed [53]. Notably, ventricular impairment due to MFS is usually global, hence any regional dysfunction warrants further clinical investigation and tissue characterisation eg with LGE to exclude concomitant pathology, (see Figure 21).
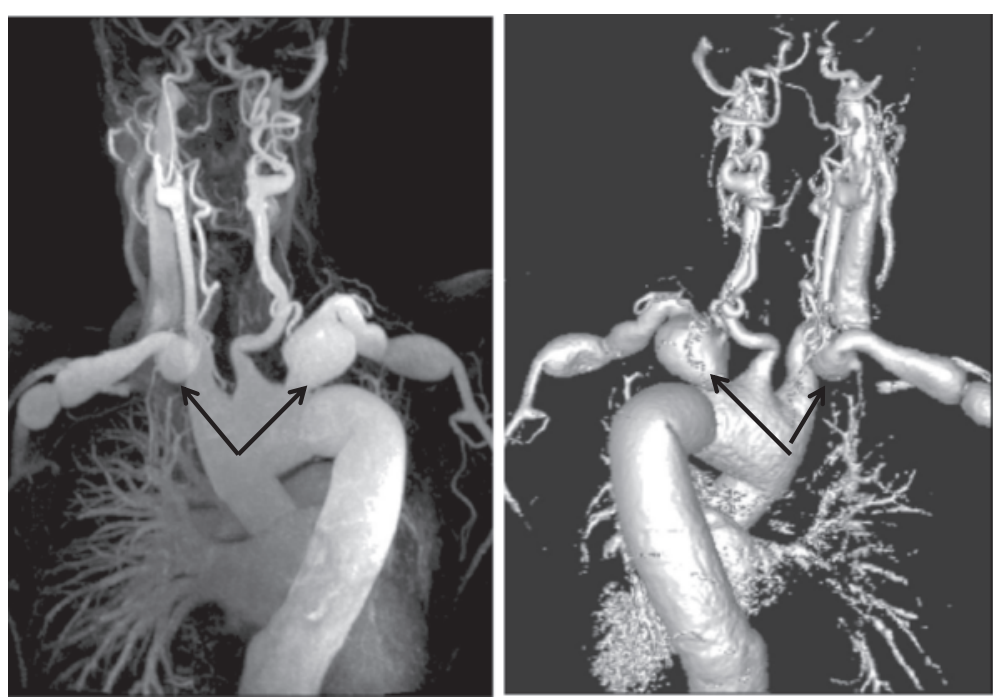

Figure 15 CE-MRA Demonstrating Bilateral Subclavian Artery Aneurysms in a Patient who has undergone Previous Aortic Root Surgery, examples highlighted by arrows. 


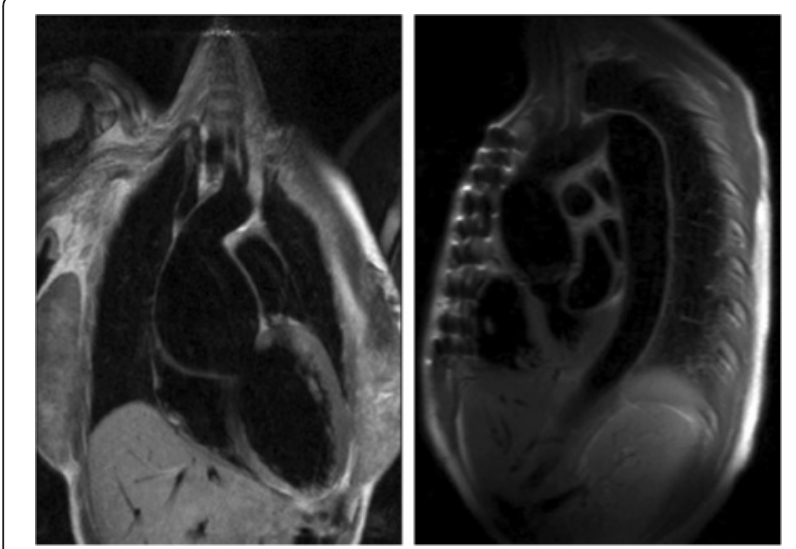

Figure 16 Black blood (spin echo) imaging before (coronal) and after (sagittal) emergency VSARR for type A dissection. Note the significant reduction in aortic root dimensions.

\section{Post surgical assessment}

After intervention or open surgery, the American guidelines advocate the use of CT to detect asymptomatic leaks or pseudoaneurysms if metallic surgical devices are likely to cause significant artefact. On a pre-discharge $\mathrm{CT}$, non-contrast images may be used to identify surgical

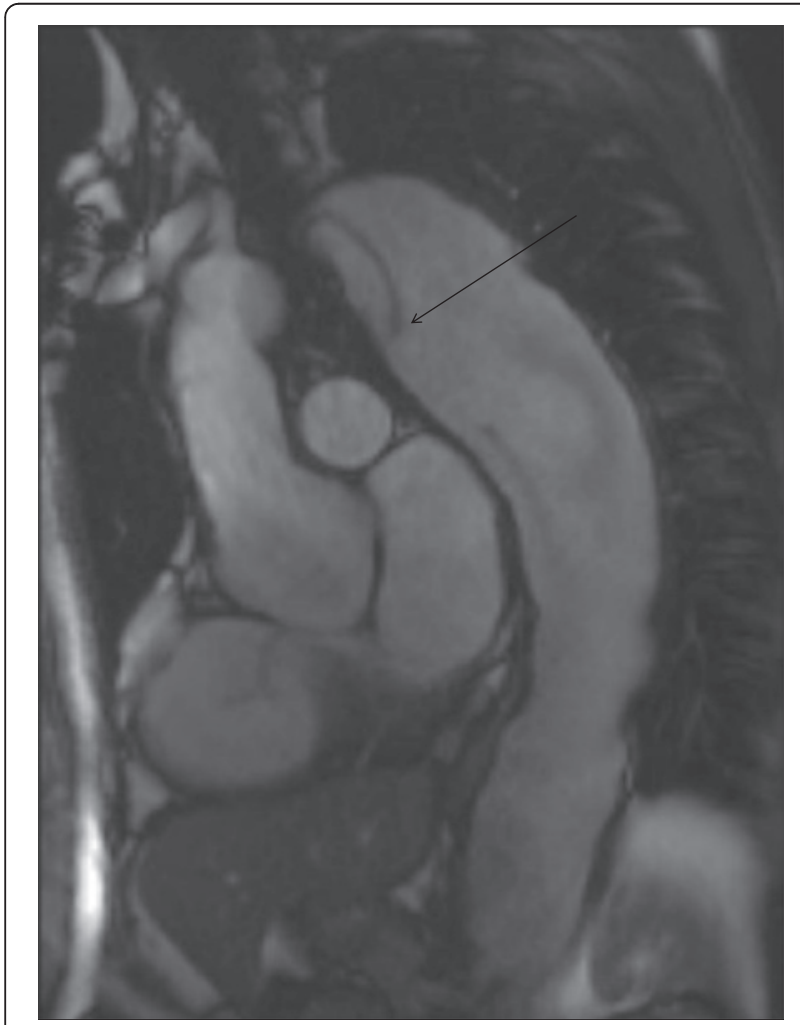

Figure 17 SSFP sagittal oblique image following emergency repair of type $A$ dissection- residual dissection in proximal arch extending into right common carotid artery. Communication between true and false lumens in proximal descending aorta is evident. Dissection flap highlighted by arrow. materials which can be difficult to distinguish from leaks on contrast-enhanced images. However use of retrospective gating means this comes with an increased dose of radiation [91].

When artefact is not an issue, and usually it is not, then CMR may be used. CMR has been used very successfully to identify complications after prosthetic replacement of the ascending aorta for over a decade [106]. A postoperative study within the index admission is advised, followed by repeats at 1,3,6 and 12 months and annually thereafter [33]. The standard protocol suggested earlier would allow comprehensive post-operative assessment.

Peri-prosthetic leaks and haemopericardium can be demonstrated on all static images and the sources determined on subsequent SSFP and velocity encoded phase imaging. Using SSFP-based cine imaging aortic measurements may be made and any residual dissection flap visualised. Slow flow and thrombus can be identified and their presence confirmed on TSE sequences [107]. If necessary, through-plane flow mapping can be used to assess true luminal flow. CMR has the added value of easily quantifying post-operative biventricular function unhindered by chest-wall anatomy. If renal function permits, then LGE should be performed (see below).

It is essential to corroborate findings with the operative notes and TOE and postoperative TTE. By doing so any graft angles or tied-off cannulation sites should not be mistaken for further dissection or pseudoaneurysm formation. In addition, proximal and distal graft anastomoses and coronary reimplantation sites can be identified.

Following a VSARR, imaging serves a number of important roles:

1. Define post-operative anatomy including surgical materials e.g. graft, Teflon strips, pledgets, Bioglue.

2. Identify haematoma or leak at proximal and distal graft anastomoses and coronary reimplantation sites. This may be localised or take the form of extensive haemopericardium.

3. Assess valvular function and look for paravalvular leaks.

4. Assess ventricular function. Perioperative myocardial infarction secondary to prolonged hypotension or difficulties with coronary reimplantation has been reported and should be readily defined on LGE.

5. Look for residual dissection and thrombus - a patent or partially thrombosed false lumen at the time of primary surgical repair is known to increase this risk [108].

6. Look for infection - either graft or sternum (See Figures 22, 23, 24, 25 and 26)

\section{Additional notes on assessment of the biophysical properties of the aortic wall and the future}

Without question CMR is an elegant technique for combining anatomical and functional assessment. In MFS 


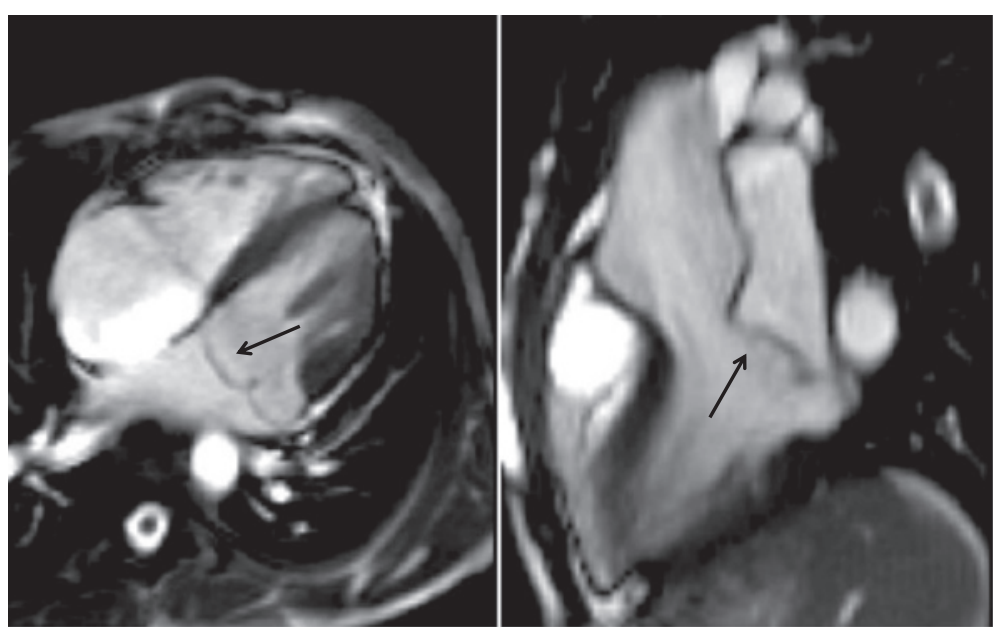

Figure 18 Bileaflet prolapse of the mitral valve at end systole (see arrow) on 4-chamber and LVOT SSFP images.

this can be exploited further to assess the biophysical properties of the aortic wall [109].

The aorta is more than just a conduit for passive blood flow. It is an elastic tube, the diameter of which varies in response to haemodynamic forces, transforming the pulsatile ventricular output into a continuous flow of blood to the peripheries. This 'distensibility' depends in large part on the elastic content, arrangement and maintenance of the vessel wall which is altered in MFS.

CMR is well placed for the assessment of aortic distensibility, the method is described and illustrated in the
CMR protocol section. This technique has been validated against echocardiographic assessments in several studies $[110,111]$. However, CMR has superior anatomical reproducibility in terms of anatomical landmarks and hence is more valuable and reproducible in terms of follow up. The process by which aortic contouring is performed is still being refined [112].

Compliance is the reciprocal of the resistance to deformation and is defined as the change in volume per unit change in pressure (microml/mm Hg). Regional aortic compliance has been studied by CMR, using a formula

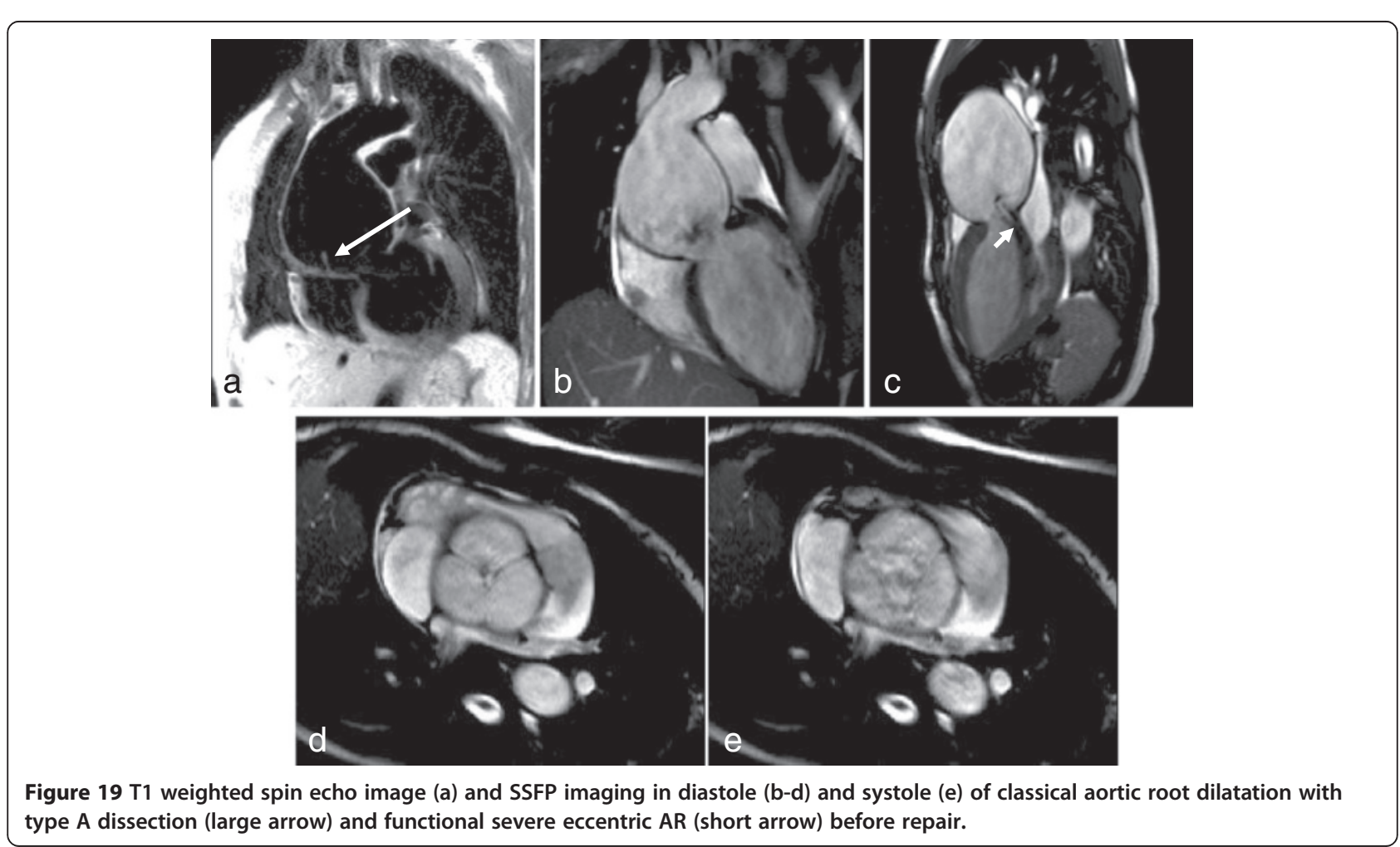



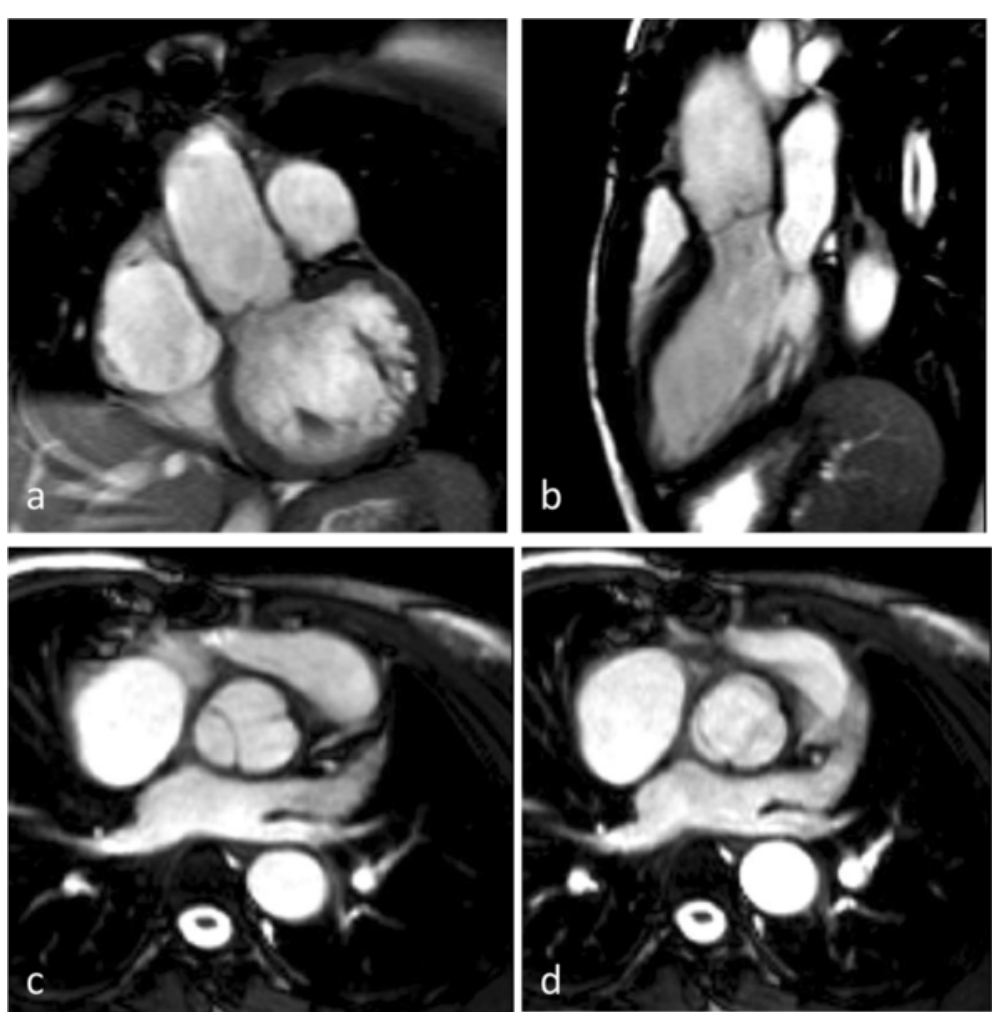

Figure 20 Diastolic (a-c) and systolic (d) frames from complete cine SSFP imaging showing appearance after successful valve- sparing surgery.

similar to that for assessment of distensibility, but using slice thickness to calculate the volume of blood in each aortic segment studied [96].

At a systemic arterial level compliance has been assessed echocardiographically in patients with MFS and used to assess response to pharmacotherapy [22,85]. In this context compliance is not assessed by means of pressure changes, but rather by the speed of propagation of the pulse wave velocity (PWV), which is generally higher as distensibility decreases. This speed of propagation is regarded as the

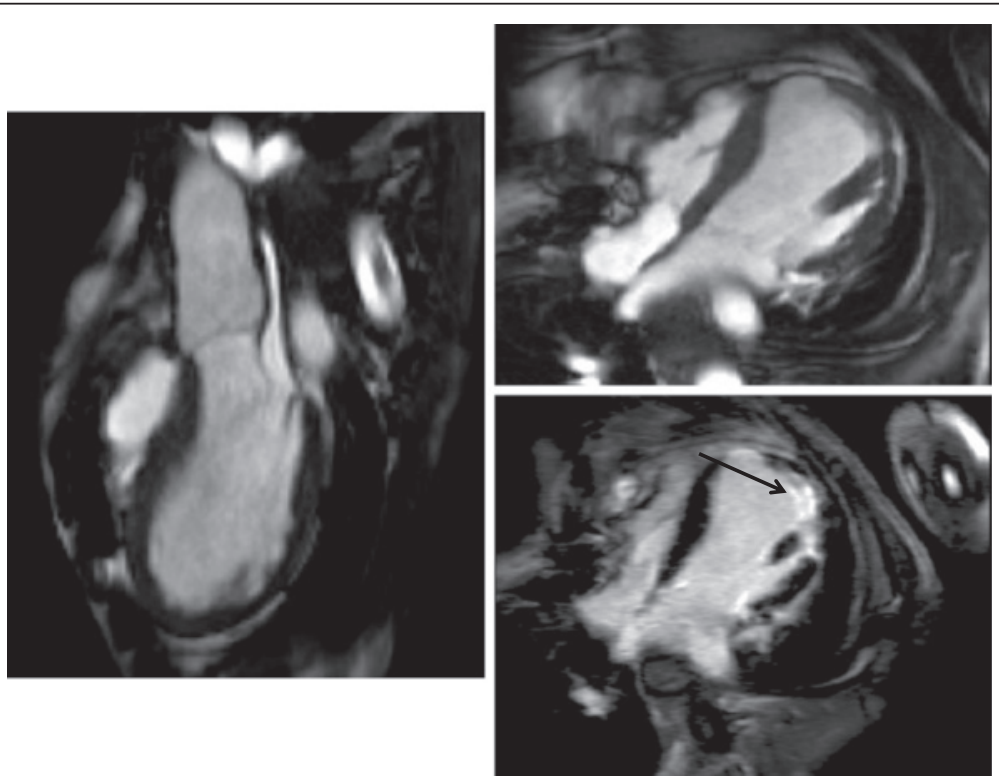

Figure 21 Anterolateral infarction with transmural enhancement in a patient with a previous aortic root repair. (SSFP images without contrast left and top; lower image is equivalent 4-chamber image following administration of gadolinium. Arrow demonstrates transmural enhancement). 


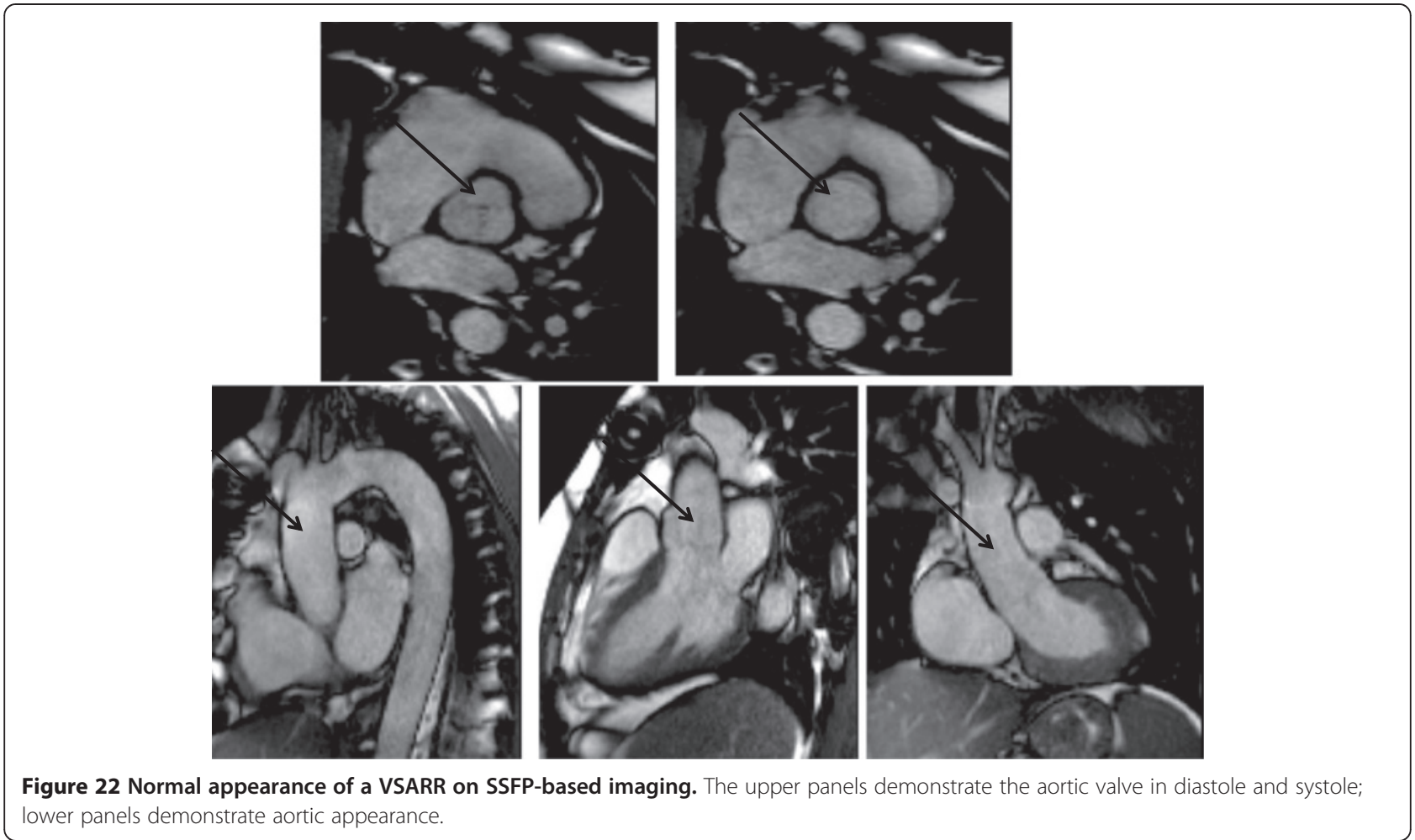

purest measure of arterial stiffness. In the aorta it is usually calculated as the ratio between the distance separating 2 points of interest and the time taken for a pressure/velocity wave to travel this distance. The feasibility of this measurement by CMR was demonstrated over 15 years ago [98]. With its unlimited views, CMR is well placed to accurately assess the length of aorta travelled by the PWV, even when chest wall or aortic anatomy is distorted. Exploiting the aortic anatomy it is possible to select an anatomic slice, usually at the level of the pulmonary bifurcation, from which a phase contrast/velocity encoded image can be acquired, in a plane perpendicular to the aortic lumen. In this one slice, phase velocity maps which can be used for quantifying blood volume flowing through the imaging plane, can be generated for 2 aortic levels [113] (See Figures 27 and 28).

Although multiple flow imaging techniques have been tried in CMR, it is the phase velocity/velocity encoding

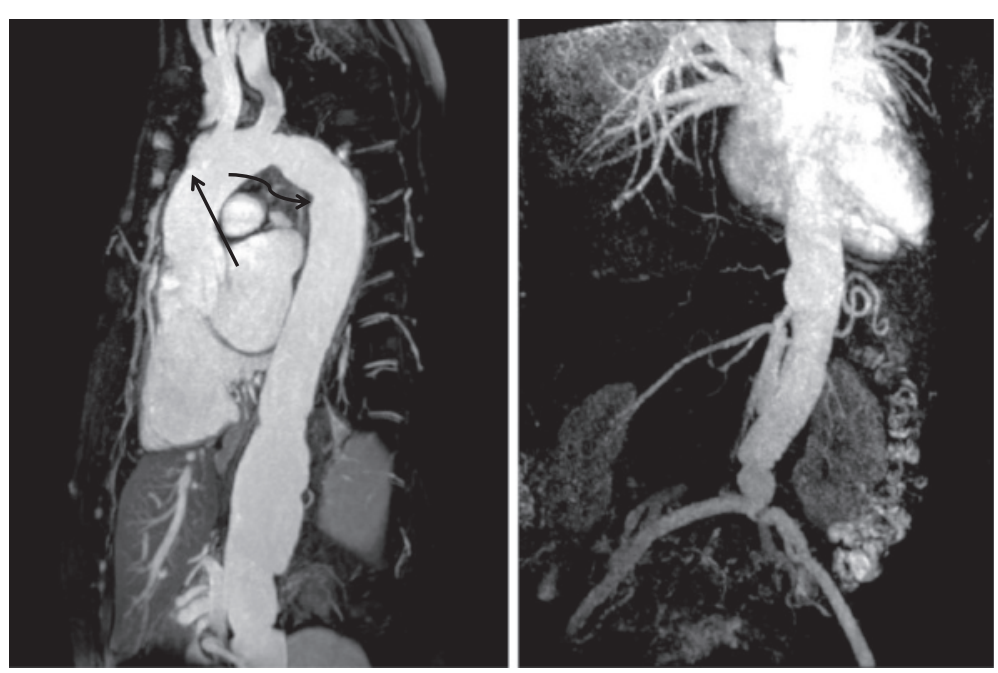

Figure 23 Tortuous abdominal aorta, previous VSARR and thoracoabdominal graft. Root replacement anastomosed to upper ascending aorta proximal to brachiocephalic artery (straight arrow). Proximal descending arch is anastomosed to thoracoabdominal gaft (curved arrow) on CE-MRA. 


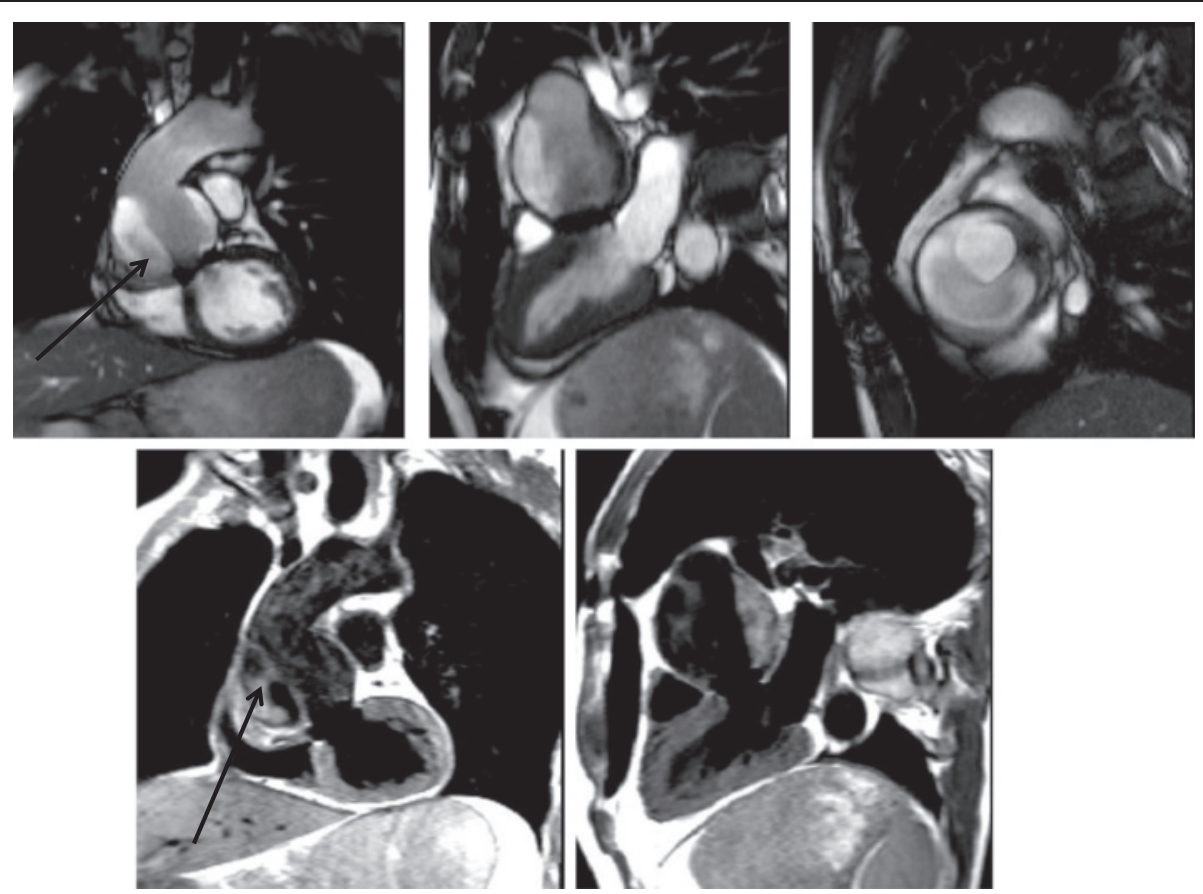

Figure 24 Haematoma outwith graft following a Bentall procedure on SSFP (coronal, sagittal and transaxial in upper panel) and black blood imaging (lower panel).

technique which is the most utilised. However, the optimal method for estimation of transit time from the resultant velocity curves remains under review [114]. Research is currently focused on a revision of the traditional 2-slice method to a two-directional in-plane velocity-encoded CMR covering the entire aorta in 3 parallel oblique-sagittal slices and, more recently, to a 4-slice breath-hold throughplane velocity-encoded CMR [115,116]. This technique may be particularly useful in predicting lack of luminal growth in the ascending aorta [117].

Indeed for some time investigators have recognised the importance of both aortic diameter and distensibility
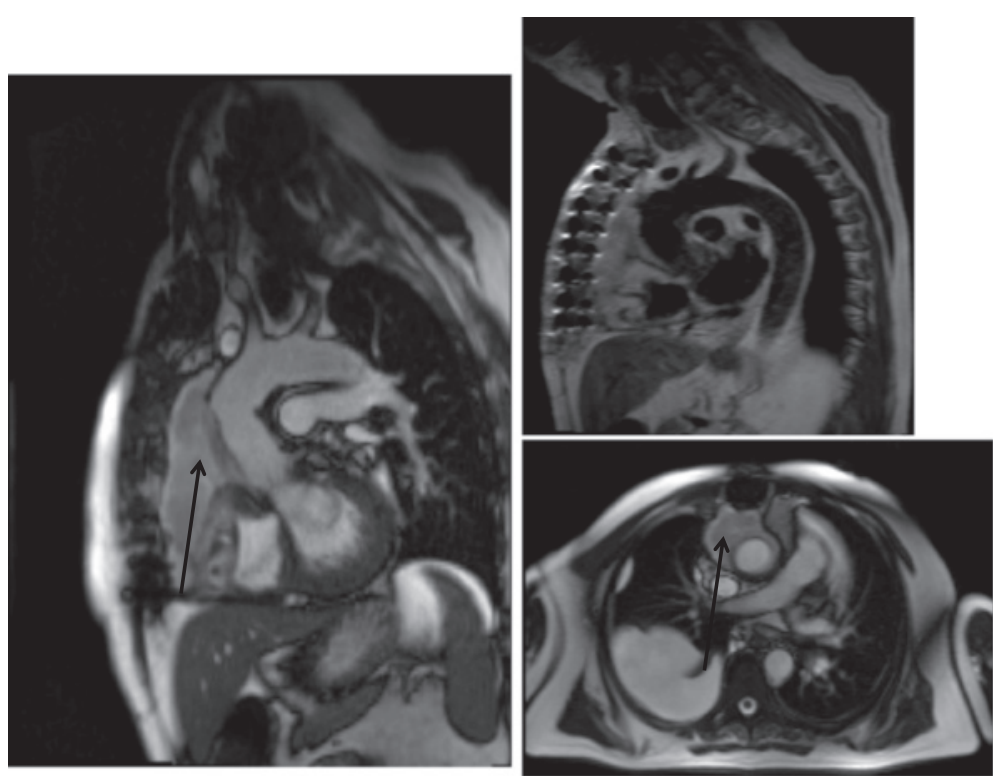

Figure 25 Para-aortic haematoma (arrowed) - previous aortic root homograft and re-do surgery (SSFP imaging in sagittal view on the left, sagittal TSE BB in upper right, SSFP imaging lower right in transaxial cut, also demonstrating right pleural effusion). 


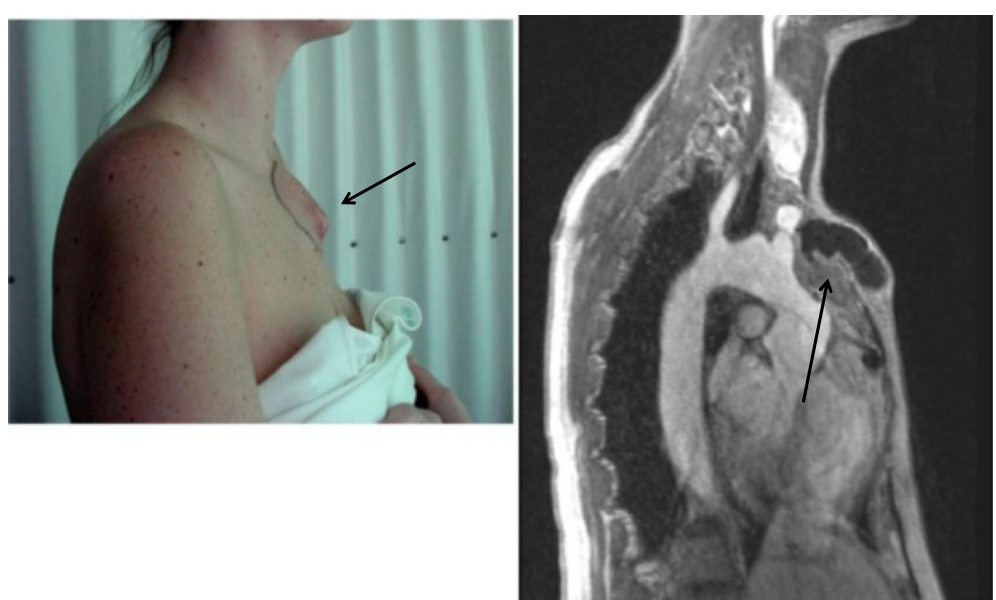

Figure 26 Subcutaneous infected collection visible externally and on CMR, courtesy of Dr Sonya Babu-Narayan.

in predicting aortic events in those with MFS [118]. For the aortic root and abdominal aorta it is the initial diameter which is the major predictor of progressive dilatation and dissection, although distensibility is also reduced; for the thoracic descending aorta, local distensibility is an independent predictor. In one study a cut off of a distensibility of $3.1 \times 10^{-3} \mathrm{mmHg}^{-1}$ was found to have sensitivity of $100 \%$ and specificity of $56 \%$ for lack of progressive dilatation. An annual assessment of aortic distensibility as well as diameters at 4 aortic levels has been proposed [119]. In addition it is possible to assess changes in aortic distensibility and PWV in response to beta-blockade in patients with MFS, although such an approach has not become routine clinical practice [120]. (It is worth noting that in those with MFS, even though beta-blockade significantly increases aortic root distensibility, it still remains
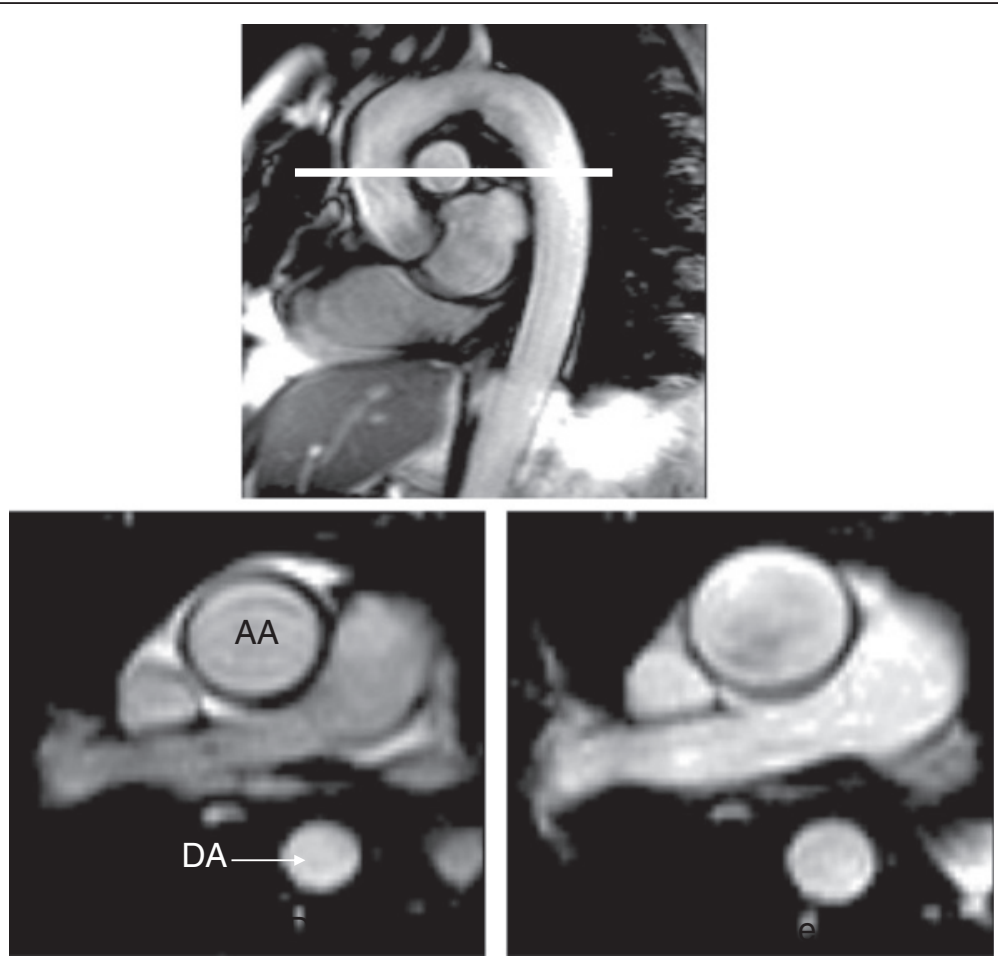

Figure 27 Upper panel shows an oblique sagittal image of the aorta demonstrating sites where flow wave velocity and regional compliance are measured. The lower images represent the oblique transverse plane in diastole (left) and systole (right), in a healthy individual. (AA ascending aorta; DA descending aorta). 


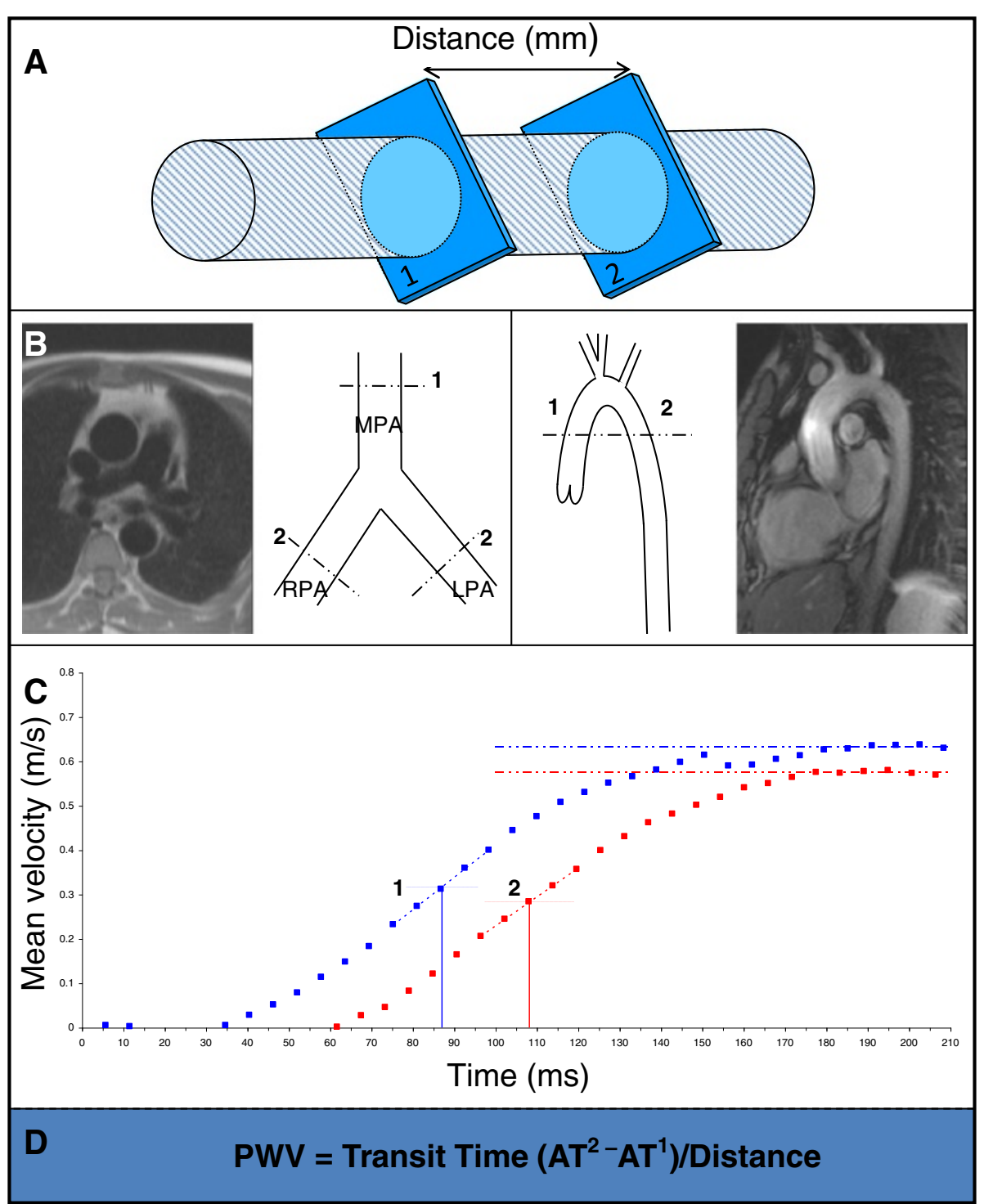

Figure 28 Demonstrates assessment of pulse wave velocity. Phase velocity acquisition across a vessel is undertaken at points 1 and 2 and the distance between them is measured. Slice prescription for the proximal pulmonary arteries and the aorta are both demonstrated. The descending and ascending aortic locations are obtained within a single slice. Transit time is defined by the difference in arrival time of the flow wave at points 1 and 2 and divided by the distance to give pulse wave velocity. (MPA main pulmonary artery; LPA left pulmonary artery; RPA right pulmonary artery). Reproduced with permission from Cardiovascular Magnetic Resonance, Second edition, Manning WJ and Pennell DJ.

significantly less than in control subjects in this study.) Other studies have demonstrated a heterogeneous response to beta-blockade with regard to aortic elasticity and, in these individuals, a combination of CMR assessment of aortic biophysical properties and blood pressure measurements may demonstrate that the aorta is already 'under strain', utilising not only elastin but also collagen to support daily 'load bearing'. These patients would be less likely to benefit from beta-blockade [121].

Distensibility may even be used as a screening tool in family members who do not appear to have the MFS phenotype [122]. Similarly, parameters of aortic compliance can be abnormal in young patients with MFS and normal aortic dimensions [123]. Although in those with MFS, distensibility may be abnormal in most parts of the aorta which are studied, it is possible that the values obtained in some segments may overlap with the normal range. In these situations, the assessment of the PWV will demonstrate the abnormalities [109]. However, a comprehensive assessment of distensibility at several aortic levels, including the aortic root, is also likely to demonstrate abnormalities in an individual with MFS and hence in a pragmatic clinical study this is an appropriate and reproducible undertaking. Of note, aging has a progressive negative effect on aortic 
compliance. However, in MFS, the values obtained are significantly different from healthy controls of an equivalent age [124].

CMR is uniquely placed to assess morphology whilst obtaining ecg-gated and spatially-encoded functional information. Therefore attention has now turned to more detailed analysis of aortic flow in MFS by means of 4D (time-resolved 3D) phase-contrast CMR [125-128]. How this contributes to negative aortic modelling has yet to be elucidated but is the subject of ongoing work [129]. In patients with MFS this technique has been used to demonstrate aortic flow disturbance and to propose a new flow-based classification of aortic disease in those with MFS [130]. Previous alternatives to this approach involved using CMR-derived parameters of the aortic wall combined with computational fluid dynamics [131] or CMR-derived aortic anatomical images reconstructed and subjected to finite element analysis to determine wall stress and hence risk of rupture [132]. The future may be one of combining the assessment of an individual's biophysical wall properties with an assessment of individual flow patterns and shear stress to refine the timing of surgical intervention and the success of both pharmacological and surgical intervention [72,125]. However this technique remains a research tool at present whilst its applications and limitations are fully elucidated $[128,133]$.

\section{Conclusion}

All guidelines recommend lifelong follow-up of the entire aorta in patients with MFS. Yet data from the Euro Heart Survey on adult congenital heart disease demonstrates that within Europe we are falling well short of this [40]. Our goal is to best utilise the multimodality techniques at our disposal to be accurate, reproducible and accessible to those with MFS. CMR is an integral part of the imaging in MFS, which dictates the timing and nature of intervention and hence dictates our patients' outcomes.

\section{Consent}

Written informed consent was obtained from the patient for the photographic image used in this review.

\section{Competing interest}

The authors have no conflict of interest to declare.

\section{Authors' contributions}

$\mathrm{HD}$ drafted the manuscript and contributed to the figures, RHM provided figures and contributed to the manuscript and its revision. All authors read and approved the final manuscript.

\section{Acknowledgements}

Peter Drivas, Harry Heyes, Andreas Hoschtitzky, Tevfik Ismail, Niall O'Keeffe, Philip Kilner, John Pepper, Mario Petrou, Mary Sheppard, Endry Willems. This project was supported by the NIHR Cardiovascular Biomedical Research Unit of Royal Brompton and Harefield NHS Foundation Trust and Imperial College London.

\section{Author details}

${ }^{1}$ Manchester Heart Centre, Manchester Royal Infirmary, Oxford Road, Manchester M13 9WL, UK. ${ }^{2}$ Royal Brompton Hospital and National Heart \& Lung Institute, Imperial College, Sydney Street, London SW3 6NP, UK.

Received: 21 November 2012 Accepted: 15 March 2013

Published: 15 April 2013

\section{References}

1. Ho NC, Tran JR, Bektas A. Marfan's syndrome. Lancet. 2005; 366(9501):1978-81.

2. Beighton P, de Paepe A, Danks D, Finidori G, Gedde-Dahl T, Goodman R, et al. International nosology of heritable disorders of connective tissue, Berlin, 1986. Am J Med Genet. 1988; 29(3):581-94.

3. De Paepe A, Devereux RB, Dietz HC, Hennekam RC, Pyeritz RE. Revised diagnostic criteria for the Marfan syndrome. Am J Med Genet. 1996; 62(4):417-26.

4. Loeys BL, Dietz HC, Braverman AC, Callewaert BL, De Backer J, Devereux RB, et al. The revised Ghent nosology for the Marfan syndrome. J Med Genet. 2010; 47(7):476-85.

5. Pyeritz RE, McKusick VA. The Marfan syndrome: diagnosis and management. N Engl J Med. 1979; 300(14):772-77.

6. Keane MG, Pyeritz RE. Medical management of Marfan syndrome. Circulation. 2008; 117(21):2802-13.

7. Hilhorst-Hofstee Y, Rijlaarsdam ME, Scholte AJ, Swart-van den Berg M, Versteegh MI, van der Schoot-van Velzen I, et al. The clinical spectrum of missense mutations of the first aspartic acid of cbEGF-like domains in fibrillin-1 including a recessive family. Hum Mutat. 2010; 31(12):E1915-27.

8. Kainulainen K, Pulkkinen L, Savolainen A, Kaitila I, Peltonen L. Location on chromosome 15 of the gene defect causing Marfan syndrome. N Engl J Med. 1990; 323(14):935-39.

9. Robinson PN, Godfrey M. The molecular genetics of Marfan syndrome and related microfibrillopathies. J Med Genet. 2000; 37(1):9-25.

10. Faivre L, Collod-Beroud G, Child A, Callewaert B, Loeys BL, Binquet C, et al. Contribution of molecular analyses in diagnosing Marfan syndrome and type I fibrillinopathies: an international study of 1009 probands. J Med Genet. 2008; 45(6):384-90.

11. Mc KV. The cardiovascular aspects of Marfan's syndrome: a heritable disorder of connective tissue. Circulation. 1955; 11(3):321-42.

12. Jondeau G, Michel JB, Boileau C. The translational science of Marfan syndrome. Heart. 2011; 97(15):1206-14.

13. Habashi JP, Judge DP, Holm TM, Cohn RD, Loeys BL, Cooper TK, et al. Losartan, an AT1 antagonist, prevents aortic aneurysm in a mouse model of Marfan syndrome. Science. 2006; 312(5770):117-21.

14. Ng CM, Cheng A, Myers LA, Martinez-Murillo F, Jie C, Bedja D, et al. TGF-beta-dependent pathogenesis of mitral valve prolapse in a mouse model of Marfan syndrome. J Clin Invest. 2004; 114(11):1586-92.

15. Loeys BL, Schwarze U, Holm T, Callewaert BL, Thomas GH, Pannu H, et al. Aneurysm syndromes caused by mutations in the TGF-beta receptor. N Engl J Med. 2006; 355(8):788-98.

16. Albornoz G, Coady MA, Roberts M, Davies RR, Tranquilli M, Rizzo JA, et al. Familial thoracic aortic aneurysms and dissections-incidence, modes of inheritance, and phenotypic patterns. Ann Thorac Surg. 2006; 82(4):1400-05.

17. Simpson CF, Kling JM, Palmer RF. Beta-aminopropionitrile-induced dissecting aneurysms of turkeys: treatment with propranolol. Toxicol App/ Pharmacol. 1970; 16(1):143-53.

18. Ose L, McKusick VA. Prophylactiv use of propranolol in the Marfan syndrome to prevent aortic dissection. Birth Defects Orig Artic Ser. 1977; 13(3C):163-69.

19. Shores J, Berger KR, Murphy EA, Pyeritz RE. Progression of aortic dilatation and the benefit of long-term beta-adrenergic blockade in Marfan's syndrome. N Engl J Med. 1994; 330(19):1335-41.

20. Danyi $P$, Elefteriades JA, Jovin IS. Medical therapy of thoracic aortic aneurysms: are we there yet? Circulation. 2011; 124(13):1469-76.

21. Brooke BS, Habashi JP, Judge DP, Patel N, Loeys B, Dietz HC 3rd. Angiotensin II blockade and aortic-root dilation in Marfan's syndrome. N Engl J Med. 2008; 358(26):2787-95.

22. Ahimastos AA, Aggarwal A, D'Orsa KM, Formosa MF, White AJ, Savarirayan $R$, et al. Effect of perindopril on large artery stiffness and aortic root diameter in patients with Marfan syndrome: a randomized controlled trial. JAMA. 2007; 298(13):1539-47. 
23. Maron BJ, Chaitman BR, Ackerman A, Bayes de Luna MJ, Corrado D, Crosson $J E$, et al. Recommendations for physical activity and recreational sports participation for young patients with genetic cardiovascular diseases. Circulation. 2004; 109(22):2807-16.

24. Murdoch JL, Walker BA, Halpern BL, Kuzma JW, McKusick VA. Life expectancy and causes of death in the Marfan syndrome. N Engl J Med. 1972; 286(15):804-08.

25. Krause KJ. Marfan syndrome: literature review of mortality studies. J Insur Med. 2000; 32(2):79-88

26. Silverman DI, Burton KJ, Gray J, Bosner MS, Kouchoukos NT, Roman MJ, Boxer M, Devereux RB, Tsipouras P. Life expectancy in the marfan syndrome. Am J Cardiol. 1995; 75:157-60.

27. Silverman DI, Gray J, Roman MJ, Bridges A, Burton K, Boxer M, et al. Family history of severe cardiovascular disease in Marfan syndrome is associated with increased aortic diameter and decreased survival. J Am Coll Cardiol. 1995; 26(4):1062-67.

28. Etter LEGLP. Arachnodactyly complicated by dislocated lens and death from rupture of dissecting aneurysm of the aorta. JAMA. 1943; 123:88-9.

29. Zagrosek AVK-BF, Polleichtner S, Schaarschmidt, Schulz-Menger J, Hemodynamic impact of surgical correction of pectus excavatum - a cardiovascular magnetic resonance study. J Cardiovasc Magn Reson. 2011; 13(Suppl 1):190.

30. Saleh RS, Finn JP, Fenchel M, Moghadam AN, Krishnam M, Abrazado M, et al. Cardiovascular magnetic resonance in patients with pectus excavatum compared with normal controls. J Cardiovasc Magn Reson. 2010; 12:73.

31. Alpendurada F, Mohiaddin R. 1039 Prevalence of cardiovascular manifestations in patients with Marfan syndrome: a cardiovascular magnetic resonance study. J Cardiovasc Magn Reson. 2008; 10(Suppl 1):A164.

32. Detaint $D$, Faivre $L$, Collod-Beroud $G$, Child AH, Loeys BL, Binquet $C$, et al. Cardiovascular manifestations in men and women carrying a FBN1 mutation. Eur Heart J. 2010; 31(18):2223-29.

33. Hiratzka LF, Bakris GL, Beckman JA, Bersin RM, Carr VF, Casey DE Jr, et al. 2010 ACCF/AHA/AATS/ACR/ASA/SCA/SCAI/SIR/STS/SVM guidelines for the diagnosis and management of patients with thoracic aortic disease: a report of the American college of cardiology foundation/American heart association task force on practice guidelines, American association for thoracic surgery, American college of radiology, American stroke association, society of cardiovascular anesthesiologists, society for cardiovascular angiography and interventions, society of interventional radiology, society of thoracic surgeons, and society for vascular medicine. Circulation. 2010; 121(13):e266-369.

34. Park SW, Hutchison S, Mehta RH, Isselbacher EM, Cooper JV, Fang J, et al. Association of painless acute aortic dissection with increased mortality. Mayo Clinic proceedings Mayo Clinic. 2004; 79(10):1252-57.

35. Khan IA, Nair CK. Clinical, diagnostic, and management perspectives of aortic dissection. Chest. 2002; 122(1):311-28.

36. Bossone E, Rampoldi V, Nienaber CA, Trimarchi S, Ballotta A, Cooper JV, et al. Usefulness of pulse deficit to predict in-hospital complications and mortality in patients with acute type A aortic dissection. Am J Cardiol. 2002; 89(7):851-55.

37. Yagdi $T$, Atay $Y$, Engin C, Mahmudov $R$, Tetik $O$, lyem $H$, et al. Impact of organ malperfusion on mortality and morbidity in acute type A aortic dissections. J Card Surg. 2006; 21(4):363-69.

38. Finkbohner R, Johnston D, Crawford ES, Coselli J, Milewicz DM. Marfan syndrome. Long-term survival and complications after aortic aneurysm repair. Circulation. 1995; 91(3):728-33.

39. Mimoun L, Detaint D, Hamroun D, Arnoult F, Delorme G, Gautier M, et al. Dissection in Marfan syndrome: the importance of the descending aorta. Eur Heart J. 2011; 32(4):443-49.

40. Engelfriet PM, Boersma E, Tijssen JG, Bouma BJ, Mulder BJ. Beyond the root: dilatation of the distal aorta in Marfan's syndrome. Heart. 2006; 92(9):1238-43.

41. Waller BF, Clary JD, Rohr T. Nonneoplastic diseases of aorta and pulmonary trunk-Part V. Clin Cardiol. 1997; 20(12):1026-28.

42. De Backer J, Loeys B, Devos D, Dietz H, De Sutter J, De Paepe A. A critical analysis of minor cardiovascular criteria in the diagnostic evaluation of patients with Marfan syndrome. Genet Med. 2006; 8(7):401-08.

43. Stuart AG, Williams A. Marfan's Syndrome and the heart. Arch Dis Child. 2007; 92(4):351-56.

44. Bhudia SK, Troughton R, Lam BK, Rajeswaran J, Mills WR, Gillinov AM, et al. Mitral valve surgery in the adult Marfan syndrome patient. Ann Thorac Surg. 2006; 81(3):843-48.
45. Gu XHY, Li Z, Han J, Chen J, Nixon JV. Marfan syndrome: echocardiographic valvular characteristics compared to histological findings. JACC. 2011; 57:E1410.

46. Underwood MJ, El Khoury G, Deronck D, Glineur D, Dion R. The aortic root: structure, function, and surgical reconstruction. Heart. 2000; 83(4):376-80.

47. Fujiseki Y, Okuno K, Tanaka M, Shimada M, Takahashi M, Kawanishi K. Myocardial involvement in the Marfan syndrome. Jpn Heart J. 1985; 26(6):1043-50

48. Kahveci G, Erkol A, Yilmaz F. Dilated cardiomyopathy in a patient with Marfan syndrome accompanied by chronic type A aortic dissection and right atrial thrombus. Intern Med. 2010; 49(23):2583-86.

49. Meijboom LJ, Timmermans J, van Tintelen JP, Nollen GJ, De Backer J, van den Berg MP, et al. Evaluation of left ventricular dimensions and function in Marfan's syndrome without significant valvular regurgitation. Am J Cardiol. 2005; 95(6):795-97.

50. De Backer JF, Devos D, Segers P, Matthys D, Francois K, Gillebert TC, et al Primary impairment of left ventricular function in Marfan syndrome. Int J Cardiol. 2006; 112(3):353-58.

51. Yetman AT, Bornemeier RA, McCrindle BW. Long-term outcome in patients with Marfan syndrome: is aortic dissection the only cause of sudden death? J Am Coll Cardiol. 2003: 41(2):329-32.

52. Kiotsekoglou A, Sutherland GR, Moggridge JC, Kapetanakis V, Bajpai A, Bunce $\mathrm{N}$, et al. Impaired right ventricular systolic function demonstrated by reduced atrioventricular plane displacement in adults with Marfan syndrome. Eur J Echocardiogr. 2009; 10(2):295-302.

53. Alpendurada F, Wong J, Kiotsekoglou A, Banya W, Child A, Prasad SK, et al. Evidence for Marfan cardiomyopathy. Eur J Heart Fail. 2010; 12(10):1085-91.

54. Gott VL, Greene PS, Alejo DE, Cameron DE, Naftel DC, Miller DC, et al. Replacement of the aortic root in patients with Marfan's syndrome. N Engl J Med. 1999; 340(17):1307-13.

55. Coady MA, Rizzo JA, Hammond GL, Mandapati D, Darr U, Kopf GS, et al. What is the appropriate size criterion for resection of thoracic aortic aneurysms? J Thorac Cardiovasc Surg. 1997; 113(3):476-91. discussion 89-91.

56. Kouchoukos NT, Dougenis D. Surgery of the thoracic aorta. N Engl J Med. 1997; 336(26):1876-88

57. Baumgartner H, Bonhoeffer $\mathrm{P}$, De Groot NM, de Haan F, Deanfield JE, Galie $\mathrm{N}$, et al. ESC Guidelines for the management of grown-up congenital heart disease (new version 2010). Eur Heart J. 2010; 31(23):2915-57.

58. Davies RR, Gallo A, Coady MA, Tellides G, Botta DM, Burke B, et al. Novel measurement of relative aortic size predicts rupture of thoracic aortic aneurysms. Ann Thorac Surg. 2006; 81(1):169-77.

59. Meijboom LJ, Vos FE, Timmermans J, Boers GH, Zwinderman AH, Mulder BJ. Pregnancy and aortic root growth in the Marfan syndrome: a prospective study. Eur Heart J. 2005; 26(9):914-20.

60. Bentall H, De Bono A. A technique for complete replacement of the ascending aorta. Thorax. 1968; 23(4):338-39.

61. Treasure T. The evolution of aortic root surgery for Marfan syndrome Interact Cardiovasc Thorac Surg. 2010; 10(3):353-55.

62. Treasure T. Elective replacement of the aortic root in Marfan's syndrome. Br Heart J. 1993; 69(2):101-03.

63. Choudhary SK, Talwar S, Kumar AS. Bentall operation with valved homograft conduit. Tex Heart Inst J. 2000; 27(4):366-68.

64. Bellhouse BJ, Bellhouse FH. Mechanism of closure of the aortic valve. Nature. 1968; 217(5123):86-7.

65. Dagum P, Green GR, Nistal FJ, Daughters GT, Timek TA, Foppiano LE, et al. Deformational dynamics of the aortic root: modes and physiologic determinants. Circulation. 1999; 100(19 Suppl):II54-62.

66. Thubrikar M, Bosher LP, Nolan SP. The mechanism of opening of the aortic valve. J Thorac Cardiovasc Surg. 1979; 77(6):863-70.

67. Kilner PJ, Yang GZ, Mohiaddin RH, Firmin DN, Longmore DB. Helical and retrograde secondary flow patterns in the aortic arch studied by threedirectional magnetic resonance velocity mapping. Circulation. 1993; 88(5 Pt 1):2235-47.

68. Yacoub MH, Gehle P, Chandrasekaran V, Birks EJ, Child A, Radley-Smith R. Late results of a valve-preserving operation in patients with aneurysms of the ascending aorta and root. J Thorac Cardiovasc Surg. 1998; 115(5):1080-90.

69. David TE, Armstrong S, Ivanov J, Feindel CM, Omran A, Webb G. Results of aortic valve-sparing operations. J Thorac Cardiovasc Surg. 2001; 122(1):39-46

70. Bechtel JFMSH, Hanke T, Charitos El, Schmidtke C, Kraatz EG, Stierle U, Misfeld M. Yacoub/David techniques for aortic root opeation: success 
and failures. In: Yankah CAWY, Hetzer R, editors. Aortic root surgery: the biological solution. Germany: Springer; 2009.

71. Miller DC. Valve-sparing aortic root replacement: current state of the art and where are we headed? Ann Thorac Surg. 2007; 83(2):S736-39. discussion S85-90.

72. Markl M, Draney MT, Miller DC, Levin JM, Williamson EE, Pelc NJ, et al. Timeresolved three-dimensional magnetic resonance velocity mapping of aortic flow in healthy volunteers and patients after valve-sparing aortic root replacement. J Thorac Cardiovasc Surg. 2005; 130(2):456-63.

73. Benedetto U, Melina G, Takkenberg JJ, Roscitano A, Angeloni E, Sinatra R Surgical management of aortic root disease in Marfan syndrome: a systematic review and meta-analysis. Heart. 2011; 97(12):955-58.

74. Excellence NIfHaC. External Aortic Root Support in Marfan Syndrome. In: Interventional Procedural Guidance. NICE; 2011: p. 394. http://publications. nice.org.uk/external-aortic-root-support-in-marfan-syndrome-ipg394/ guidance.

75. Dhillon JS, Randhawa GK, Straehley CJ, McNamara JJ. Late rupture after dacron wrapping of aortic aneurysms. Circulation. 1986; 74(3 Pt 2):111-14.

76. Pepper J, John Chan K, Gavino J, Golesworthy T, Mohiaddin R, Treasure T. External aortic root support for Marfan syndrome: early clinical results in the first 20 recipients with a bespoke implant. J R Soc Med. 2010; 103 (9):370-75.

77. Treasure T, Pepper JR. Aortic root surgery in Marfan syndrome. Heart 2011; 97(12):951-52.

78. Wang ZG, Massimo CG, Li M, Pan SL, Zhang HK, Jing W, et al. Deployment of endograft in the ascending aorta to reverse type A aortic dissection. Asian J Surg. 2003; 26(2):117-19.

79. Pasic M, Hummel M, Hetzer R. Combined aortic surgery and implantation of a left ventricular assist device. N Engl J Med. 2002; 346(9):711.

80. Rajagopal K, Rogers JG, Lodge AJ, Gaca JG, McCann RL, Milano CA, et al. Two-stage total cardioaortic replacement for end-stage heart and aortic disease in Marfan syndrome: case report and review of the literature. $J$ Heart Lung Transplant. 2009; 28(9):958-63.

81. De Backer J. The expanding cardiovascular phenotype of Marfan syndrome. Eur J Echocardiogr. 2009; 10(2):213-15.

82. Kramer CM, Barkhausen J, Flamm SD, Kim RJ, Nagel E. Standardized cardiovascular magnetic resonance imaging (CMR) protocols, society for cardiovascular magnetic resonance: board of trustees task force on standardized protocols. J Cardiovasc Magn Reson. 2008; 10:35.

83. Hundley WG, Bluemke D, Bogaert JG, Friedrich MG, Higgins CB, Lawson MA, et al. Society for cardiovascular magnetic resonance guidelines for reporting cardiovascular magnetic resonance examinations. J Cardiovasc Magn Reson. 2009; 11:5.

84. Kabirdas D, Scridon C, Brenes JC, Hernandez AV, Novaro GM, Asher CR Accuracy of transthoracic echocardiography for the measurement of the ascending aorta: comparison with transesophageal echocardiography. Clin Cardiol. 2010; 33(8):502-07.

85. Kiotsekoglou A, Moggridge JC, Saha SK, Kapetanakis V, Govindan M, Alpendurada $F$, et al. Assessment of aortic stiffness in marfan syndrome using two-dimensional and Doppler echocardiography. Echocardiography. 2011; 28(1):29-37.

86. Kiotsekoglou A, Sutherland GR, Moggridge JC, Nassiri DK, Camm AJ, Child $\mathrm{AH}$. The unravelling of primary myocardial impairment in Marfan syndrome by modern echocardiography. Heart. 2009; 95(19):1561-66.

87. Shiga T, Wajima Z, Apfel CC, Inoue T, Ohe Y. Diagnostic accuracy of transesophageal echocardiography, helical computed tomography, and magnetic resonance imaging for suspected thoracic aortic dissection: systematic review and meta-analysis. Arch Intern Med. 2006; 166(13):1350-56.

88. Hagan PG, Nienaber CA, Isselbacher EM, Bruckman D, Karavite DJ, Russman $P L$, et al. The international registry of acute aortic dissection (IRAD): new insights into an old disease. JAMA. 2000; 283(7):897-903.

89. LePage MA, Quint LE, Sonnad SS, Deeb GM, Williams DM. Aortic dissection: $\mathrm{CT}$ features that distinguish true lumen from false lumen. AJR Am J Roentgenol. 2001; 177(1):207-11.

90. Lin FY, Devereux RB, Roman MJ, Meng J, Jow VM, Jacobs A, et al. Assessment of the thoracic aorta by multidetector computed tomography: age- and sex-specific reference values in adults without evident cardiovascular disease. J Cardiovasc Comput Tomogr. 2008; 2(5):298-308.
91. Fleischmann D, Liang DH, Mitchell RS, Miller DC. Pre- and postoperative imaging of the aortic root for valve-sparing aortic root repair (V-SARR). Semin Thorac Cardiovasc Surg. 2008; 20(4):365-73.

92. Feuchtner GM, Alkadhi H, Karlo C, Sarwar A, Meier A, Dichtl W, et al. Cardiac CT angiography for the diagnosis of mitral valve prolapse: comparison with echocardiography1. Radiology. 2010; 254(2):374-83.

93. Ha HI, Seo JB, Lee SH, Kang JW, Goo HW, Lim TH, et al. Imaging of Marfan syndrome: multisystemic manifestations. Radiographics. 2007; 27(4):989-1004

94. Farrelly C, Davarpanah A, Keeling AN, Sheehan J, Ragin A, Yaghmai V, et al. Low dose dual-source CT angiography of the thoracic aorta. Int J Cardiovasc Imaging. 2011; 27(7):1025-34.

95. Meijboom LJ, Groenink M, van der Wall EE, Romkes H, Stoker J, Mulder BJ. Aortic root asymmetry in marfan patients; evaluation by magnetic resonance imaging and comparison with standard echocardiography. Int J Card Imaging. 2000; 16(3):161-68.

96. Mohiaddin RH, Underwood SR, Bogren HG, Firmin DN, Klipstein RH, Rees RS, et al. Regional aortic compliance studied by magnetic resonance imaging: the effects of age, training, and coronary artery disease. Br Heart J. 1989; 62(2):90-6.

97. Rueckert D, Burger P, Forbat SM, Mohiaddin RD, Yang GZ. Automatic tracking of the aorta in cardiovascular MR images using deformable models. IEEE Trans Med Imaging. 1997; 16(5):581-90.

98. Mohiaddin RH, Firmin DN, Longmore DB. Age-related changes of human aortic flow wave velocity measured noninvasively by magnetic resonance imaging. J Appl Physiol. 1993; 74(1):492-97.

99. Burman ED, Keegan J, Kilner PJ. Aortic root measurement by cardiovascular magnetic resonance: specification of planes and lines of measurement and corresponding normal values. Circ Cardiovasc Imaging. 2008; 1(2):104-13.

100. Bireley WR 2nd, Diniz LO, Groves EM, Dill K, Carroll TJ, Carr JC. Orthogonal measurement of thoracic aorta luminal diameter using ECG-gated highresolution contrast-enhanced MR angiography. J Magn Reson Imaging. 2007; 26(6):1480-85

101. Kaiser T, Kellenberger CJ, Albisetti M, Bergstrasser E, Valsangiacomo Buechel ER. Normal values for aortic diameters in children and adolescents-assessment in vivo by contrast-enhanced CMR-angiography. J Cardiovasc Magn Reson. 2008; 10:56.

102. Amano Y, Takahama K, Kumita S. Non-contrast-enhanced MR angiography of the thoracic aorta using cardiac and navigator-gated magnetizationprepared three-dimensional steady-state free precession. J Magn Reson Imaging. 2008; 27(3):504-09.

103. Potthast S, Mitsumori L, Stanescu LA, Richardson ML, Branch K, Dubinsky TJ, et al. Measuring aortic diameter with different MR techniques: comparison of three-dimensional (3D) navigated steady-state freeprecession (SSFP), 3D contrast-enhanced magnetic resonance angiography (CE-MRA), 2D T2 black blood, and 2D cine SSFP. J Magn Reson Imaging. 2010; 31(1):177-84.

104. Pepper J, Golesworthy T, Utley M, Chan J, Ganeshalingam S, Lamperth M, et al. Manufacturing and placing a bespoke support for the Marfan aortic root: description of the method and technical results and status at one year for the first ten patients. Interact Cardiovasc Thorac Surg. 2010; 10(3):360-65.

105. Han Y, Peters DC, Salton CJ, Bzymek D, Nezafat R, Goddu B, et al. Cardiovascular magnetic resonance characterization of mitral valve prolapse. JACC Cardiovasc Imaging. 2008; 1(3):294-303.

106. Mesana TG, Caus T, Gaubert J, Collart F, Ayari R, Bartoli J, et al. Late complications after prosthetic replacement of the ascending aorta: what did we learn from routine magnetic resonance imaging follow-up? Eur J Cardiothorac Surg. 2000; 18(3):313-20.

107. Riley $\mathrm{P}$, Rooney S, Bonser R, Guest P. Imaging the post-operative thoracic aorta: normal anatomy and pitfalls. Br J Radiol. 2001; 74(888):1150-58.

108. Albrecht F, Eckstein F, Matt P. Is close radiographic and clinical control after repair of acute type $A$ aortic dissection really necessary for improved long-term survival? Interact Cardiovasc Thorac Surg. 2010; 11(5):620-25.

109. Groenink M, de Roos A, Mulder BJ, Verbeeten B Jr, Timmermans J, Zwinderman $\mathrm{AH}$, et al. Biophysical properties of the normal-sized aorta in patients with Marfan syndrome: evaluation with MR flow mapping. Radiology. 2001; 219(2):535-40. 
110. Adams JN, Brooks M, Redpath TW, Smith FW, Dean J, Gray J, et al. Aortic distensibility and stiffness index measured by magnetic resonance imaging in patients with Marfan's syndrome. Br Heart J. 1995; 73(3):265-69.

111. Baumgartner D, Baumgartner C, Schermer E, Engl G, Schweigmann U, Matyas $\mathrm{G}$, et al. Different patterns of aortic wall elasticity in patients with Marfan syndrome: a noninvasive follow-up study. J Thorac Cardiovasc Surg. 2006; 132(4):811-19.

112. Lalande A, Khau van Kien P, Salve N, Ben Salem D, Legrand L, Walker PM et al. Automatic determination of aortic compliance with cine-magnetic resonance imaging: an application of fuzzy logic theory. Invest Radiol. 2002; 37(12):685-91.

113. Metafratzi ZM, Efremidis SC, Skopelitou AS, De Roos A. The clinical significance of aortic compliance and its assessment with magnetic resonance imaging. J Cardiovasc Magn Reson. 2002; 4(4):481-91.

114. Dogui A, Redheuil A, Lefort M, DeCesare A, Kachenoura N, Herment A, et al. Measurement of aortic arch pulse wave velocity in cardiovascular MR: comparison of transit time estimators and description of a new approach. J Magn Reson Imaging. 2011; 33(6):1321-29.

115. Westenberg JJ, de Roos A, Grotenhuis HB, Steendijk P, Hendriksen D, van den Boogaard PJ, et al. Improved aortic pulse wave velocity assessment from multislice two-directional in-plane velocity-encoded magnetic resonance imaging. J Magn Reson Imaging. 2010; 32(5):1086-94.

116. Kroner ES VGR, Scholte AJ, van den Boogard PJ, Hendriksen D, Kroft L, Groenink M, Radonic T, Bax JJ, de Roos A, Reiber JH, Westenberg JJ. Accuracy of aortic pulse wave velcity assessment with velocity-encoded MRI: validation in patients with Marfan syndrome. SCMR/Euro CMR Joint Scientific Sessions. France: Nice; 2011: p. 071.

117. Kroner ES, Scholte AJ, de Koning PJ, van den Boogaard PJ, Kroft LJ, van de Geest RJ, et al. MRI-assessed regional pulse wave velocity for predicting absence of regional aorta luminal growth in marfan syndrome. Int $J$ Cardiol. 2012.

118. Witte PD RT, Laan K, Zwinderman AH, Mulder BJ, Groenink M. Aortic distensibility is a predictor for aortic events in patients with marfan syndrome, a 12 year-survival analysis. JACC. 2010; 50(10):0735-1097.

119. Nollen GJ, Groenink M, Tijssen JG, Van Der Wall EE, Mulder BJ. Aortic stiffness and diameter predict progressive aortic dilatation in patients with Marfan syndrome. Eur Heart J. 2004; 25(13):1146-52.

120. Groenink M, de Roos A, Mulder BJ, Spaan JA, van der Wall EE. Changes in aortic distensibility and pulse wave velocity assessed with magnetic resonance imaging following beta-blocker therapy in the Marfan syndrome. Am J Cardiol. 1998; 82(2):203-8.

121. Nollen GJ, Westerhof BE, Groenink M, Osnabrugge A, van der Wall EE, Mulder BJ. Aortic pressure-area relation in Marfan patients with and without beta blocking agents: a new non-invasive approach. Heart. 2004; 90(3):314-8

122. Fattori R, Bacchi Reggiani L, Pepe G, Napoli G, Bna C, Celletti F, et al. Magnetic resonance imaging evaluation of aortic elastic properties as early expression of Marfan syndrome. J Cardiovasc Magn Reson. 2000; 2(4):251-6.

123. Eichhorn JG, Krissak R, Rudiger HJ, Ley S, Arnold R, Boese J, et al. Compliance of the normal-sized aorta in adolescents with Marfan syndrome: comparison of MR measurements of aortic distensibility and pulse wave velocity. RoFo. Fortschr Geb Rontgenstr Nuklearmed. 2007; 179(8):841-6.

124. Westenberg JJ SA, Vaskova Z, Groenink M, van der Geest RJ, Labadie G, van den Boogaard PJ, Radonic TR, Hilhorst-Hofstee Y, Kroft LJ, de Roos A, Reiber $\mathrm{JH}$. Relation between age and aortic wall compliance in the Marfan syndrome: evaulation with Velocity-Encoded MRI. SCMR Scientific Sessions. Pheonix, AZ: BioMed Central; 2010: p. 9.

125. Kvitting JP, Ebbers T, Wigstrom L, Engvall J, Olin CL, Bolger AF. Flow patterns in the aortic root and the aorta studied with time-resolved, 3dimensional, phase-contrast magnetic resonance imaging: implications for aortic valve-sparing surgery. J Thorac Cardiovasc Surg. 2004; 127(6):1602-7

126. Bogren HG, Mohiaddin RH, Yang GZ, Kilner PJ, Firmin DN. Magnetic resonance velocity vector mapping of blood flow in thoracic aortic aneurysms and grafts. J Thorac Cardiovasc Surg. 1995; 110(3):704-14.

127. Weigang E, Kari FA, Beyersdorf F, Luehr M, Etz CD, Frydrychowicz A, et al, Flow-sensitive four-dimensional magnetic resonance imaging: flow patterns in ascending aortic aneurysms. Eur J Cardiothorac Surg. 2008; 34(1):11-6.
128. Bieging ET, Frydrychowicz A, Wentland A, Landgraf BR, Johnson KM, Wieben $O$, et al. In vivo three-dimensional MR wall shear stress estimation in ascending aortic dilatation. J Magn Reson Imaging. 2011; 33(3):589-97.

129. Pitcher ACT, Suttie J, Francis JM, Leeson P, Blair E, Wordsworth BP, Forfar JC, Markl M, Neubauer SN, Petersen SE. 4D-Flow CMR Demonstrates the Regional Distribution of Aortic Flow Disturbance in Marfan Syndrome. Heart. 2011; 97(Suppl 1):A62.

130. Pitcher ACT, Suttie J, Francis JM, Leeson P, Blair E, Wordsworth BP, Forfar JC, Myerson SG, Markl M, Neubauer SN, Petersen SE. Visualisation of aortic flow disturbance in Marfan syndrome by 4D phase-contrast CMR. SCMR/Euro CMR Joint Scientific Sessions. Nice, France: BioMed Central; 2011: p. 201.

131. Camarda JA EM, Dholakia RJ, Wang H, Kwon S, LaDisa JF, Samyn MM. Biophysical properties of the aorta in patients with Marfan syndrome and related connective tissue disorders: evaluation with MRI and computational fluid dynamics modeling. SCMR/Euro CMR Joint Scientific Sessions. Nice, France: BioMed Central; 2011: p. 219.

132. Borghi A, Wood NB, Mohiaddin RH, Xu XY. 3D geometric reconstruction of thoracic aortic aneurysms. Biomed Eng Online. 2006; 5:59.

133. Markl M, Wallis W, Harloff A. Reproducibility of flow and wall shear stress analysis using flow-sensitive four-dimensional MRI. J Magn Reson Imaging. 2011; 33(4):988-94.

134. Habermann CR, Weiss F, Schoder V, Cramer MC, Kemper J, Wittkugel O, et al. MR evaluation of dural ectasia in Marfan syndrome: reassessment of the established criteria in children, adolescents, and young adults. Radiology. 2005; 234(2):535-41.

\section{doi:10.1186/1532-429X-15-33}

Cite this article as: Dormand and Mohiaddin: Cardiovascular Magnetic Resonance in Marfan syndrome. Journal of Cardiovascular Magnetic Resonance 2013 15:33.

\section{Submit your next manuscript to BioMed Central and take full advantage of:}

- Convenient online submission

- Thorough peer review

- No space constraints or color figure charges

- Immediate publication on acceptance

- Inclusion in PubMed, CAS, Scopus and Google Scholar

- Research which is freely available for redistribution

Submit your manuscript at www.biomedcentral.com/submit
C) BioMed Central 